\title{
Biases caused by the instrument bandwidth and beam width on simulated brightness temperature measurements from scanning microwave radiometers
}

\author{
V. Meunier ${ }^{1}$, U. Löhnert ${ }^{2}$, P. Kollias ${ }^{1}$, and S. Crewell ${ }^{2}$ \\ ${ }^{1}$ Department of Atmospheric and Oceanic Sciences, McGill University, Montreal, Canada \\ ${ }^{2}$ Institute for Meteorology and Geophysics, University of Cologne, Cologne, Germany \\ Correspondence to: V. Meunier (veronique.meunier2@mcgill.ca)
}

Received: 17 September 2012 - Published in Atmos. Meas. Tech. Discuss.: 1 November 2012

Revised: 3 April 2013 - Accepted: 8 April 2013 - Published: 7 May 2013

\begin{abstract}
More so than the traditional fixed radiometers, the scanning radiometer requires a careful design to ensure high quality measurements. Here the impact of the radiometer characteristics (e.g., antenna beam width and receiver bandwidth) and atmospheric propagation (e.g. curvature of the Earth and vertical gradient of refractive index) on scanning radiometer measurements are presented. A forward radiative transfer model that includes all these effects to represent the instrument measurements is used to estimate the biases. These biases are estimated using differences between the measurement with and without these characteristics for three commonly used frequency bands: K, V and W-band. The receiver channel bandwidth errors are less important in $\mathrm{K}$-band and W-band. Thus, the use of a wider bandwidth to improve detection at low signal-to-noise conditions is acceptable at these frequencies. The biases caused by omitting the antenna beam width in measurement simulations are larger than those caused by omitting the receiver bandwidth, except for V-band where the bandwidth may be more important in the vicinity of absorption peaks. Using simple regression algorithms, the effects of the bandwidth and beam width biases in liquid water path, integrated water vapour, and temperature are also examined. The largest errors in liquid water path and integrated water vapour are associated with the beam width errors.
\end{abstract}

\section{Introduction}

Ground-based microwave radiometers have often been used in a stand-alone zenith-pointing mode measuring integrated amounts of water vapour and liquid water as well as temperature and water vapour profiles (Staelin, 1966; Blaskovic et al., 1987; Güldner and Spänkuch, 1999). Recently, an expansion of the use of scanning radiometers in atmospheric research has been observed. Scanning radiometers have been used in studies of temperature and water vapour in the boundary layer (Martin et al., 2006a; Crewell and Löhnert, 2007; Schween et al., 2011) and in tomographic retrieval of cloud liquid water and water vapour (Huang et al., 2008; Padmanabhan et al., 2009). In particular, co-scanning radarradiometer measurements are gaining a lot of attraction due to the complimentary nature of their observations. Radars provide information on winds, particle size distributions, precipitation and cloud, while radiometers will give information on the profiles of temperature and water vapour, and the integrated amount of liquid water content. Thus, the complementary information of these instruments can lead to a better understanding and characterisation of clouds (Frisch et al., 1995; Shupe et al., 2008; Saavedra et al., 2012) and thermodynamic profiles (Westwater et al., 1983; Bianco et al., 2005; Gaffard et al., 2003; Löhnert et al., 2008).

Although the advantages of co-scanning radar-radiometers measurements are evident, such observation geometries contain the risks of potential biases in the radiometer measurements due to unaccounted instrument characteristics. For example, at low elevations, the effects of atmospheric refractivity may become an issue. The wide beam widths of the instrument will result in ground emissions data contamination during the lowest elevation scans. Radars have narrower beam width than radiometers, because they use elevation angles that are very close to the horizon in order to 
get more information in the atmosphere, i.e., precipitation. Radiometers generally do not scan quasi-horizontally and, thus, may have wider beam widths. Another reason is that the atmospheric-signal to instrument-noise ratio depends on the size of the antenna for radars, but not for radiometers. Furthermore, the need to maintain scan rates suitable for radar observations will force radiometers to shorten their integration times to keep up with the radar scans, possibly causing increased noise in their measurements. The power received by a radiometer is also proportional to the receiver bandwidth. Thus, the use of a wide receiver bandwidth can result in higher signal-to-noise conditions and, thus, shorter integration time that is highly desirable in scanning conditions. However, the use of a wide receiver bandwidth could lead to errors caused by non-negligible changes of the absorption coefficient (equivalently changes in brightness temperature) within the bandwidth range.

Han and Westwater (2000) (hereafter HW00) investigated the uncertainty factors of radiometer tipping curves that are used to calibrate K-band channels. In their study, they investigated the impact of Earth curvature and antenna beam width for elevation angles ranging between zenith $\left(90^{\circ} \mathrm{el}-\right.$ evation) and $14.5^{\circ}$. HW00 report that, for the studied elevation angles, the effect of the vertical gradient of the refractive index of air was negligible. They also mentioned that the effect of earth curvature can, for the most part, be corrected. The beam width error increases with increasing beam width, elevation angle, and water vapour amount, but corrections can be applied if the antenna side lobes can be neglected. HW00 conclude that tipping data should not include elevation angles less than $20^{\circ}$, especially for antenna with beam widths greater than $6^{\circ}$. Although the study was conducted in the context of microwave radiometer calibration, the issues raised can be applied to the new scanning strategies.

Here, the work of HW00 is expanded by adding lower elevation angles and additional wavelengths that are also widely used for retrieving atmospheric quantities, i.e., liquid water path, temperature and humidity profiles. For this application, it is common to assume the beam width and the bandwidth to be zero in order to simplify the calculations. This paper is to provide a rough estimate of the bias error caused by using such assumptions. The goal of this study is to motivate the scientific community to include these effects in their forward models. This paper does not seek to quantify the biases in detail as most of these can be reduced either by including the beam width and bandwidth in their calculation or correcting for them. First, the forward model framework used in this study is described. Then, the effects that channel bandwidth, antenna beam width, refractive index and Earth curvature have on the measurements of the microwave radiometers and the the retrieved atmospheric products are investigated. Finally, a summary of the most important effects will be provided.

\section{Experimental design}

\subsection{Forward model}

This study uses a radiometer instrument model and a forward radiative transfer model to study the measurement errors caused by the radiometer's design characteristics and the atmospheric propagation conditions. The input to the model consists of an atmospheric sounding, which provides information on pressure, height, temperature, water vapour density and cloud liquid water content. Other input variables include the microwave frequencies, beam width, bandwidth, and elevation angles of the radiometer. The levels of the model are directly those of the sounding that has 70 vertical levels at a resolution of $1 \mathrm{~km}$. The different soundings are to be discussed later.

The input to the radiometer is proportional to the atmospheric radiance $I\left(\mathrm{~W} \mathrm{~m}^{-2} \mathrm{sr}^{-1} \mathrm{GHz}^{-1}\right)$ of the incoming radiation, and in the absence of scattering, it is given by

$$
\begin{aligned}
& I(f, \theta)=\int_{\theta^{\prime}} G\left(\theta^{\prime}-\theta\right)\{B(f, T=2.7 \mathrm{~K}) t(f, 0, \infty) \\
& \left.\quad+\int_{0}^{\infty} \alpha(f, s) t(f, 0, s) B[f, T(s)] \mathrm{d} s\right\} \mathrm{d} \theta^{\prime},
\end{aligned}
$$

where $\theta$ is elevation angle, $\theta^{\prime}$ is the elevation angle of a specific ray of the beam, $G\left(\theta^{\prime}-\theta\right)$ is antenna gain, $f$ is frequency, $B(f, T=2.7 \mathrm{~K})$ is the emitted radiation of the cosmic radiating background, $t(f, 0, \infty)$ is the total transmission from top of the atmosphere to the surface, $s$ is the slant path length, $\alpha(f, s)$ is the absorption coefficient at $s$ in $\mathrm{km}^{-1}$, $t(f, 0, s)$ is the atmospheric transmission between the surface to $s$ at frequency $f$, and $B[f, T(s)]$ is the Planck function with temperature at $s, T(s)$ (i.e., Petty, 2006; Huang et al., 2008). This equation must be discretized for numerical calculation. This is done as

$$
\begin{aligned}
& I(f, \theta)=\frac{1}{\beta} \sum_{v} k_{\mathrm{bw}} \sum_{\omega} w_{\omega}\left\{t\left(f_{v}, 0, \infty\right) B(f, T=2.7 \mathrm{~K})\right. \\
& \left.\quad+\sum_{i} a\left(f_{v}, s_{i}\right) t\left(f_{v}, 0, s_{i}\right) B\left[f_{v}, T\left(s_{i}\right)\right]\right\},
\end{aligned}
$$

where $\beta$ is the channel bandwidth, $k_{\mathrm{bw}}$ is a constant to normalise the beam width, $\omega$ is the index for each of the angles used to create the beam width, $w_{\omega}$ is the Gaussian weight for each of the angles in the beam width, $v$ is the index for each of the frequencies used to create the bandwidth, $f_{v}$ represents each of the frequencies in the bandwidth, $i$ is the index of the number of atmospheric layers and $B\left[f_{v}, T\left(s_{i}\right)\right]$ is the radiance for each layer. The radiance of each level of the atmosphere is determined using the Planck function

$$
B\left[f, T\left(s_{i}\right)\right]=\frac{2 h f_{v}^{3}}{c^{2}} \frac{1}{e^{h f_{v} / k T_{i}}-1},
$$




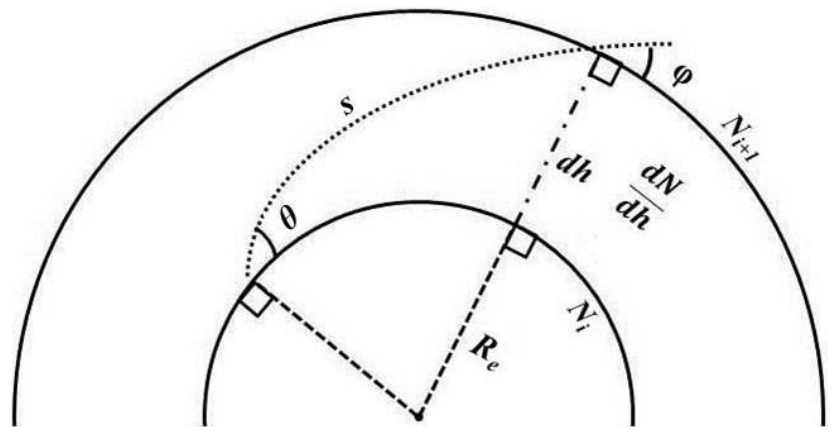

Fig. 1. A sketch showing the propagation at the lowest levels in the atmosphere. The full curved lines represent the 2 first levels of the soundings. On each of these levels is a value of the refractivity of the level $N_{i}$ and $N_{i+1}$ that are the refractivity for the first and the second level, respectively. The small dashed lines represent the Earth's radius $\left(R_{\mathrm{e}}\right)$. The dash dot line represent the height difference between the level (dh). This is also the thickness of the layer between the two model levels. In this layer, there is a value of vertical gradient of refractive index $(\mathrm{dN} / \mathrm{dh})$. The small dotted line is the path followed by the beam in the propagation with path length $(s)$ between the two levels. $\theta$ is the elevation angles of the radiometer, and $\phi$ is the entrance angle of the next layer.

where $h$ is Planck's constant, $c$ is the speed of light, $k$ is Boltzmann's constant and $T_{i}$ is the average temperature of the layer (HW00). The radiance, $I(f, \theta)$, is converted to brightness temperature (TB) by solving the Planck function for temperature at the end of the radiative transfer calculation.

The attenuation calculation performed by this forward model can use either the Rosenkranz (1998) or the Liebe (1989) gas absorption models. The Rosenkranz version includes the correction found by Turner et al. (2009), but this correction was not included in the Liebe version. This being said including or not this correction would not change the results shown here. Both of these absorption models show some temperature bias in the absorption coefficients in both $\mathrm{K}$-band and V-band, but in V-band Liebe's code is a better fit to the measurements (Hewison et al., 2006). In this case, the Liebe MPM- 89 code is used for the calculation of the absorption of the atmospheric gases. Hewison et al. (2006) found that Liebe's absorption model was the closest to the measurements although it still over-estimates the absorption. The cloud absorption model used in this study is that of Stogryn (1995). The forward model has several other cloud absorption codes that can be used. This code was chosen because it was found that it yields TB that are more consistent with radiometer measurements (Cadeddu and Turner, 2011). The relation between attenuation in $\mathrm{dB}$ and that in $\mathrm{km}^{-1}$ is given by

$\alpha\left(\mathrm{km}^{-1}\right)=0.2303 \alpha\left(\frac{\mathrm{dB}}{\mathrm{km}}\right)$.
The forward model has three different radio propagation schemes permitting the study of different aspects of the atmospheric propagation. In all the different schemes, the slant path, $s$, is calculated for each atmospheric layer in the model (Fig. 1). The simplest form of beam propagation is done by assuming the Earth has no curvature and the vertical gradient of refractive index of the atmosphere is not taken into account. In this case, the slant path through the atmosphere is given is given by

$s=\frac{\mathrm{dh}}{\sin (\theta)}$,

where "dh" is the thickness of the atmospheric layer and $\theta$ is the elevation angle (Petty, 2006). A slightly more complex scheme takes into account the curvature of the Earth, but assumes a constant vertical gradient of refractive index $\left(-390 \mathrm{~km}^{-1}\right)$. This gradient of refractive index is equivalent to the bending that would occur from the curvature of the Earth alone if the Earth was $4 / 3$ times larger than it actually is. In this case,

$s=\sqrt{\left[a_{\mathrm{e}} \sin (\varphi)\right]^{2}+\mathrm{dh}^{2}+2 a_{\mathrm{e}} \mathrm{dh}}-a_{\mathrm{e}} \sin (\varphi)$,

where $a_{\mathrm{e}}=4 / 3 R_{\mathrm{e}}, R_{\mathrm{e}}$ is the earth radius (assumed to be constant at $6357 \mathrm{~km}$ ), and $\varphi$ is the entrance angle into the layer (Doviak and Zrnic, 2006). Between each layer in the atmosphere, the angle of the propagating ray changes because of the combination of the curvature of the Earth and that of the ray when the gradient of refractive index is constant. In order to take this into account in the propagation, we calculate at each layer in the model a new angle, the entrance angle. This angle is calculated as

$\varphi=\sin ^{-1}\left[\frac{s \cos \left(\varphi_{o}\right)}{a_{\mathrm{e}}}+\sin \left(\varphi_{o}\right)\right]$,

where $\varphi_{o}$ is the preceding entrance angle or, for the first layer, the instrument's elevation angle. The final scheme is the most complex and includes both the Earth curvature and the actual vertical gradient of the refractive index. The latter is given by

$\frac{\mathrm{dN}}{\mathrm{dh}}=\frac{N_{i+1}-N_{i}}{\mathrm{dh}}$,

where $N_{i+1}$ is the refractive index at the top of the $i$ th layer and $N_{i}$ is at the bottom of the layer. The refractive index was calculated using the refractivity calculation included in the Liebe (1989) absorption code. In this propagation scheme, the $s$ calculation depends on the gradient of refractive index as

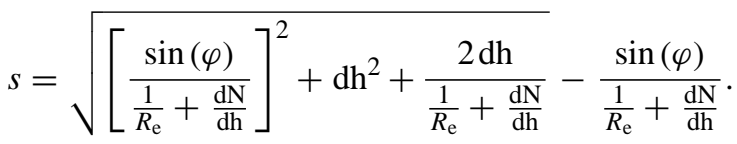


In this scheme, the change of the refractive gradient with height also affects the entrance angle of the layer, which is calculated as

$\varphi=\sin ^{-1}\left[s \cos \left(\varphi_{o}\right)\left(\frac{1}{R_{\mathrm{e}}}+\frac{\mathrm{dN}}{\mathrm{dh}}\right)+\sin \left(\varphi_{o}\right)\right]$.

Detailed comparisons of the forward model output using the three different propagation schemes for different frequency bands will be used to quantify the errors caused by omitting only the vertical gradient of the refractive index and omitting both the curvature of the Earth and the vertical gradient of the refractive index.

In addition to radio propagation, the forward model also takes into account the antenna beam width and the channel bandwidth of the radiometer. Typical antenna patterns of radiometer systems show a Gaussian shape and a side lobe suppression of better than $-30 \mathrm{~dB}$ (Rose et al., 2005). The beam width calculation is done using a Gaussian quadrature following Huang et al. (2008) neglecting the effects of the side lobes. The evaluation of the beam width is one dimensional in the elevation axis. This assumes an axis-symmetric beam pattern that excludes the azimuthal effects inside the beam. Azimuthal scanning is not implemented in the model and, thus, a horizontally homogeneous atmosphere is assumed. In the case where the beam partially hits the ground, the radiances of that part of the beam are changed to

$$
\mathrm{TB}_{\text {hit ground }}=\varepsilon \mathrm{TB}_{\text {ground }}+(1-\varepsilon) \mathrm{TB}_{\text {sky }} \text {, }
$$

where $\varepsilon$ is the emissivity of the ground, $\mathrm{TB}_{\text {ground }}$ is the blackbody radiances emitted by the ground represented by the lowest level in the soundings, and $\mathrm{TB}_{\text {sky }}$ is the emission from the atmosphere from all directions. $\mathrm{TB}_{\text {sky }}$ is calculated as

$\mathrm{TB}_{\text {sky }}=\int_{0}^{90} \cos (\xi) \mathrm{TB}(\xi) d \xi$,

where $\xi$ includes 89 angles form $1^{\circ}$ to $90^{\circ}$. In reality this contribution will depend on the actual position of the radiometer and the emissivity of the ground. This emissivity changes with ground cover type and wetness as well as the frequency and polarisation of the radiometer. Here, we assume the emissivity to be 0.9 . The receiver bandwidth modelling is achieved by subdividing the bandwidth into a series of discrete frequencies that are used in the forward model. The radiances are calculated for each of these frequencies and then, they are simply integrated to create the effect of channel bandwidth. In this study, the shape of the bandwidth is idealised to a "square" filter. However, this could easily be changed to other filter shapes, once they are known, by changing the weights of each of the radiances. This is important, as in reality, the specified center frequency does not necessarily correspond to the bandwidth filter shape averaged frequency (Crewell et al., 2001).

\subsection{Retrieval model}

A simple retrieval algorithm is used to calculate the response of certain retrieved atmospherics parameters to the errors for both K-band and V-band. The parameters that were derived are integrated water vapour (IWV), liquid water path (LWP) and temperature $(T)$. Both the IWV and LWP are derived using only the $23.8 \mathrm{GHz}$ and $31.4 \mathrm{GHz} \mathrm{K}$-band frequencies for elevation angles $90,42,30,19.2,10.2$, and $5.4^{\circ}$. The W-band was not included in the algorithm, although an improvement of $50 \%$ can be made using the $90 \mathrm{GHz}$ frequency in LWP retrievals because of its sensitivity to clouds (Crewell and Löhnert, 2003). The LWP was derived from TB measurements as

$\mathrm{LWP}=c_{0}+\sum_{f}\left(c_{1 f} \mathrm{~TB}_{f}+c_{2 f} \mathrm{~TB}_{f}^{2}\right)$,

where $\mathrm{TB}_{f}$ is the brightness temperature defined previously in Kelvin for each of the frequency channels, $f$ and $c_{0}, c_{1 f}$ and $c_{2 f}$ are the regression coefficients (Löhnert and Crewell, 2003). The same equation is used for the IWV regression, but the regression coefficients are different. All statistical errors refer to the path integrated amounts and only the LWP and IWV are mapped to zenith values (the temperature profiles are not). The temperature profiles retrieval is based on 7 V-band frequencies $(51.26,52.28,53.86,54.94,56.66,57.3$ and $58 \mathrm{GHz}$ ) where the first 3 frequencies are used only in zenith pointing and the last 4 consider all the elevations angles used for the IWV and LWP retrievals. The temperature was derived using a linear regression from TB measurements as

$T_{i}=d_{o}+\sum_{f} \sum_{\theta} d_{1 f \theta} \mathrm{TB}_{f \theta}$,

where $d_{0}$ and $d_{1 f \theta}$ are the regression coefficients and $i$ is the index for each layer of the sounding (Crewell and Löhnert, 2007). LWP retrievals are performed on clear air cases as well as cloudy cases. This is done because the bias error caused by not taking the beam width or bandwidth into account could lead to an apparent liquid water signature in the water vapour sensitive $\mathrm{K}$-band and $\mathrm{W}$-band frequencies.

\subsection{Climatological soundings}

The standard mid-latitude summer and winter, tropical summer and subarctic summer atmospheric profiles from McClatchey et al. (1972) are used to describe the atmospheric structure and properties (Fig. 2). The soundings are treated as climatological standards and are representative of the typical conditions encountered in areas where radar-radiometer systems operate and cover a wide variety of climates. However, it is to be noted that some results are sounding dependent such as the some of the beam width errors. Therefore, some of the effects mentioned here will dependent on the 

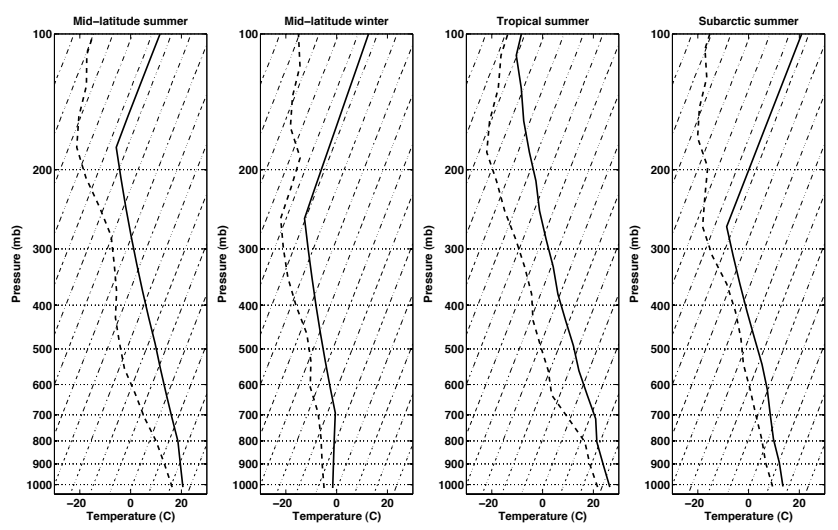

Fig. 2. The McClatchey climatological soundings (in skew-T plots) used in this study (from left to right): mid-latitude summer, midlatitude winter, tropical summer, and subarctic summer. In these plots, temperature is in full line, dew point temperature is in dashed.

atmospheric situation. These soundings are clear air soundings. Since radars are used for hydrometeors detection, we have added a $1 \mathrm{~km}$ thick horizontally homogeneous cloud at a height of $2 \mathrm{~km}$ and with a liquid water path of $300 \mathrm{~g} \mathrm{~m}^{-2}$ to the previously described soundings. In this cloud, the water vapour was changed from the original values in the climatology soundings to the saturated values. We have not added precipitation as scattering effects must also be accounted for and are, for the moment, not included in the forward model.

\subsection{Radiometer characteristics}

The radiometer characteristics used for this study are chosen from the designs of commercially available and experimental instruments. The group of instruments used to create these ranges is listed in Table 1. The frequencies incorporated in the model are the traditional frequencies in K-band (here 15 to $35 \mathrm{GHz}$ ) and V-band (here $50-60 \mathrm{GHz}$ ). The K-band, covering the $22.235 \mathrm{GHz}$ water vapour absorption line, provides information on the amounts of liquid water and water vapour (Fig. 3). The V-band dominated by the $60 \mathrm{GHz}$ oxygen absorption band that provides information on the temperature distribution in the lower troposphere. In addition to the traditional frequencies, the W-band $(94 \mathrm{GHz})$ frequencies are also added because they are strongly sensitive to liquid water signal. They are widely used in the millimetre wavelength radar community and, thus, are interesting for possible radar-radiometer synergetic measurements. This frequency band is also used in radiometry. The Department of Energy's (DOE) Atmosphere Radiation Measurement (ARM) Climate research Facility has added 3-channel radiometers that include the $90 \mathrm{GHz}$ to several of their sites. ARM also uses the Radiometer Physics GmbH dual-frequency radiometer that works at $90 \mathrm{GHz}$ and $150 \mathrm{GHz}$ (Turner et al., 2009). In this study, we examine $201 \mathrm{~K}$-band frequencies, $101 \mathrm{~V}$-band frequencies and $56 \mathrm{~W}$-band frequencies with each frequency

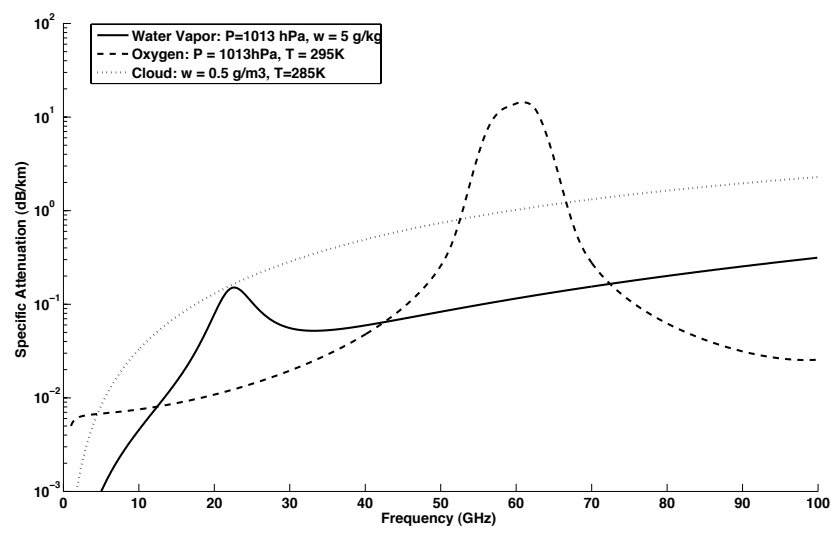

Fig. 3. One-way specific attenuation curves of water vapour (dashed), oxygen (line) and cloud (dotted) in $\mathrm{dB} \mathrm{km}^{-1}$.

being separated by $0.1 \mathrm{GHz}$. The beam widths chosen range from 0.5 to $10^{\circ}$ at half power full width, while the channel bandwidths range between 100 and $1000 \mathrm{MHz}$. These settings cover the specifications of current microwave instruments. The elevation angles from 0.5 to $90^{\circ}$ are chosen to emphasise the low elevation scans required when performing boundary layer scans or when scanning with radars. The latter usually scan low to the horizon in order to be able to detect hydrometeors in the boundary layer at a distance. HW00 used elevation starting at $14.5^{\circ}$ in their work on tipping curve calibrations. We included some of these higher elevation angles for the sake of comparison, as well as an indication for the radiometers that still use the traditional high elevation scans. A summary of the instrument characteristics used in this study can be found in Table 2 .

\section{Analysis}

In this section, each of the radiometer instrument characteristics will be examined individually. An interpretation of their observed biases will be provided along with an assessment on their impact on the retrieved geophysical parameters of interest. The results will be shown as errors in TB. The TB bias errors are defined as

$\mathrm{TB}_{\text {error }}=\mathrm{TB}_{\text {assumption }}-\mathrm{TB}_{\text {reality }}$,

while the equivalent bias in opacity is defined as

$\tau_{\text {error }}=\frac{\tau_{\text {assumption }}}{\tau_{\text {reality }}}$.

The equivalent bias in opacity is only given for K-band and W-band. In V-band, it is changes in the temperature profile of the atmosphere that drives changes in TB measurements not so much changes opacity. The assumption is defined as being the approximation of the idealised radiometer generally used in forward models where antenna beam width and channel 
Table 1. A sample of current commercial and experimental radiometers that inspired the instrument design characteristics included in this study, where HPFW is half power full width.

\begin{tabular}{lrrll}
\hline $\begin{array}{l}\text { Radiometer } \\
\text { name }\end{array}$ & $\begin{array}{r}\text { Beam width } \\
\text { (HPFW) }\end{array}$ & Bandwidth & Frequency bands & References \\
\hline ADMIRARI & $5^{\circ}-6.53$ & $400 \mathrm{MHz}$ & $\mathrm{X}$ and K band (3 frequencies) & Battaglia et al. (2010) \\
ASMUWARA & $7.9-10^{\circ}$ & $300-4000 \mathrm{MHz}$ & $\mathrm{K}, \mathrm{V}, \mathrm{mm}$ bands and IR (9 frequencies) & $\begin{array}{l}\text { Martin et al. (2006b) } \\
\text { Rose et al. (2005) Radiometer } \\
\text { HATPRO }\end{array}$ \\
$2.5-3.5^{\circ}$ & $100-2000 \mathrm{MHz}$ & $\mathrm{K}$ and V band (14 frequencies) & Physic GmbH (2010) \\
LWP-90-150 & $1.5-1.8^{\circ}$ & $2000 \mathrm{MHz}$ & $\mathrm{W}$ and D band (2 frequencies) & Cadeddu (2011) \\
MWR3C & $3.0-3.5^{\circ}$ & $300-1900 \mathrm{MHz}$ & $\mathrm{K}$ and W band (3 frequencies) & Cadeddu (2012) \\
MICCY & $0.4-0.9^{\circ}$ & $250-1000 \mathrm{MHz}$ & $\mathrm{K}, \mathrm{V}$, and W band (22 frequencies) & Crewell et al. (2001) \\
MP-3000A & $2.2-6.1^{\circ}$ & $400 \mathrm{MHz}$ & $\mathrm{K}$ and V band (12 frequencies) & Liljegren (2002), Ware et al. (2003) \\
MTP-5 & $<0.9-3^{\circ}$ & $\sim 4000 \mathrm{MHz}$ & V band (1 frequency) & Kipp and Zonen (2012), Gaikovich (2004) \\
\hline
\end{tabular}

Table 2. Summary of the instrument characteristics included in the study.

\begin{tabular}{ll}
\hline Frequencies & $\begin{array}{l}\text { K-band }(15-35 \mathrm{GHz}), \\
\text { V-band }(50-60 \mathrm{GHz}), \\
\text { W-band }(94-95.5 \mathrm{GHz})\end{array}$ \\
\hline Bandwidths (MHz) & $\begin{array}{l}100,200,300,400,500, \\
600,700,800,900,1000\end{array}$ \\
\hline Beam widths $\left(^{\circ}\right)$ & $\begin{array}{l}0.5,1,2,3,4,5,6,7, \\
8,9,10\end{array}$ \\
\hline Elevation angles $\left(^{\circ}\right)$ & $0.5,2,4,6,8,10,12,14$, \\
& $20,25,30,45,60,90$ \\
\hline
\end{tabular}

bandwidth are considered to be delta functions. The reality includes the width of either the bandwidth or the beam width. The effects are studied individually meaning that when the bandwidth is studied the beam width is neglected and vice versa for the beam width studies.

\subsection{Receiver bandwidth effect}

\subsubsection{K-band simulations}

In K-band, the TB curvature changes are caused by the water vapour absorption line at $22.235 \mathrm{GHz}$ (Fig. 3). The most prominent feature in the error analysis is a dipole of under and over estimation that is associated with this absorption peak (Fig. 4). The area of under-estimation on the low frequency side of the absorption peak is associated to the negative curvature associated to the low frequency wing of the absorption peak where the atmosphere is most transparent (Fig. 5). This leads to an under-estimation of TB if the delta-function bandwidth approximation is used. The maximum value of the under-estimation is $-0.8 \mathrm{~K}$ (opacity 0.993 ) at an elevation of $10^{\circ}$ for a bandwidth of $1 \mathrm{GHz}$ in the mid-latitude summer sounding (Fig. 4). The area of overestimation is associated to the positive curvature of the ab-
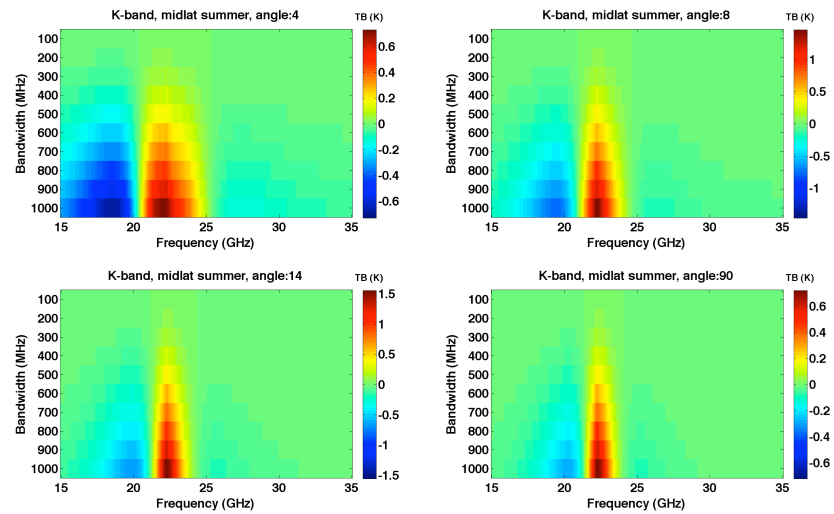

Fig. 4. The errors associated to the channel bandwidth effect in TB differences for K-band frequencies using the mid-latitude summer atmospheric profile. The TB differences are defined as the TB calculated from a forward model without bandwidth minus the TB calculated from a forward model with bandwidth.

sorption peak, which is linked to the atmosphere being more opaque (Fig. 5). The maximum value of the over-estimation occurs at elevations between 10 and $14^{\circ}$ for the largest bandwidth and is of $1.5 \mathrm{~K}$ (opacity 1.015 ) again with the midlatitude summer sounding (Fig. 4). As expected, the largest errors are linked to the largest bandwidths. For bandwidths less than $200 \mathrm{MHz}$, the errors caused by the bandwidth approximation are negligible and can be ignored. At the lowest elevation angle used in this study $\left(0.5^{\circ}\right)$, the location of the dipole has shifted to lower frequencies. The curvature changes that cause the errors are displaced by the broadening of the water vapour absorption peak at low elevation angles (Fig. 5). There are small differences in the errors caused by the bandwidth approximation between the soundings. The maximum errors values in the winter mid-latitude sounding are of $1.4 \mathrm{~K}$ (opacity 1.015 ) for the over-estimation and of $-0.6 \mathrm{~K}$ (opacity 0.991 ) for the under-estimation. The tropical summer sounding has $1.4 \mathrm{~K}$ (opacity 1.018 ) for the overestimation and $-0.7 \mathrm{~K}$ (opacity 0.990 ) for under-estimation. 


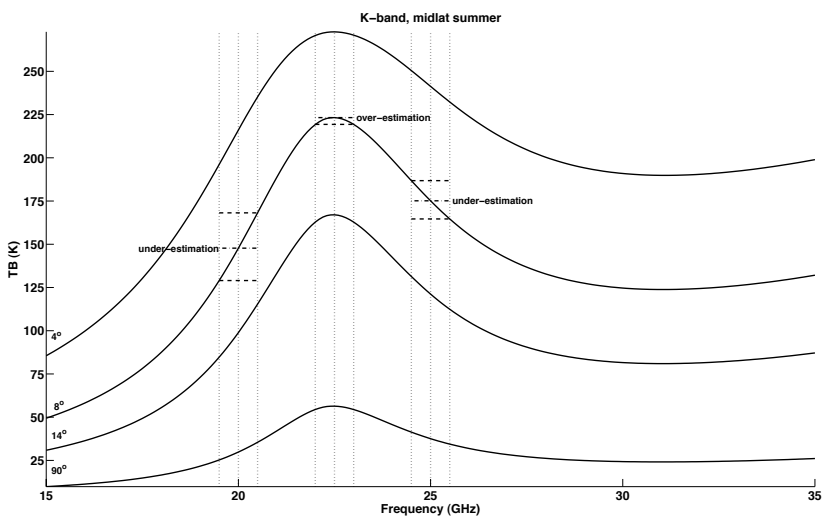

Fig. 5. Explanation of over and under estimations that cause the bandwidth errors, which are linked to the curvature of the TB vs. frequency curve in K-band for the mid-latitude summer sounding. The vertical dotted lines represent the $1 \mathrm{GHz}$ bandwidth (centre line is centre frequency). The short horizontal dashed lines are used to locate the intersection of the extremities of the bandwidth and the dashed dot line locates the centre frequency on the TB curve. These additional lines help to visually see that the over-estimation and under-estimation errors are linked to the curvature of the TB curve.

The subarctic summer sounding has $1.5 \mathrm{~K}$ (opacity 1.016) in over-estimation and $-0.7 \mathrm{~K}$ (opacity 0.990 ) in underestimation. The widths in frequency of the over-estimation and under-estimation areas depend on the atmospheric structure. The mid-latitude winter sounding exhibits the narrowest widths and the tropical sounding has the widest. These are mainly caused by the increase of water vapour in the tropical sounding. The small difference between the soundings shows that these results are somewhat sounding independent. The curvature of the TB spectrum (Fig. 5) leads to areas of over-estimation and under-estimation errors that have an impact on the retrieval's solutions. The K-band measurements are used in retrievals to determine the IWV and LWP of the atmosphere (zenith corrected). The mid-latitude soundings were used to illustrate this. The errors for both retrieved parameters are more important at low elevations angles for the summer sounding at the largest bandwidths (Fig. 6). For IWV, the largest errors are $-0.12 \mathrm{~kg} \mathrm{~m}^{-2}\left(-0.01 \mathrm{~kg} \mathrm{~m}^{-2}\right)$ at $10^{\circ}$ elevation with the summer (winter) sounding for the largest bandwidth. For both soundings, the errors in IWV decrease with increasing elevation angle to become negligible for zenith pointing instruments. For LWP, the errors due to channel bandwidth are below $1 \mathrm{~g} \mathrm{~m}^{-2}$ for all settings and can be neglected. The LWP retrievals prove insensitive to the band widths because the $31.4 \mathrm{GHz}$ channel that is key to the retrieval is located in a window region where the curvature of TB with frequency is small.
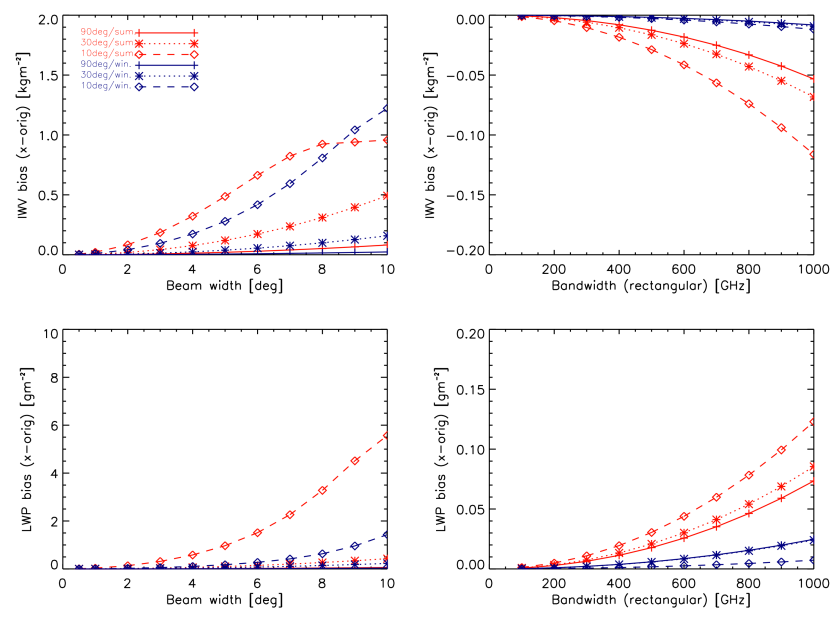

Fig. 6. The error in the retrieved IWV (in $\mathrm{kg} \mathrm{m}^{-2}$ ) and LWP (in $\mathrm{g} \mathrm{m}^{-2}$ ) zenith corrected caused by the errors in TB by not taking into account antenna beam width (right) or bandwidth (left). The errors are shown for both the mid-latitude summer (red) and the mid-latitude winter soundings (blue) for elevation angles $10^{\circ}$ (dash square), $30^{\circ}$ (dot star), and $90^{\circ}$ (line + ).

\subsubsection{V-band simulations}

Absorption in the V-band is caused by the oxygen complex (Fig. 3), which consists of several closely spaced absorption lines. Because of pressure broadening, the individual lines only significantly appear within the spectrum under low-pressure conditions. With increasing opacity, i.e., low elevation angles and/or high frequency, the V-band channels become saturated and, thus, any change in TB caused by the bandwidth approximation will have negligible effect. For this reason, frequencies above $55 \mathrm{GHz}$ at all elevation angles are saturated (Fig. 7). Starting at $4^{\circ}$, an area of overestimation moves up in frequency as the elevation angle increases $\left(50 \mathrm{GHz}\right.$ at $4^{\circ}$ to $53 \mathrm{GHz}$ at $30^{\circ}$ ) (Fig. 8). This area of over-estimation is attributed to the positive curvature of the TB spectrum ahead of the saturation around $55 \mathrm{GHz}$ (Fig. 7). This is associated to opaque frequencies that receive their entire signal from close ranges from the lower atmosphere. The maximum value of the over-estimation in $\mathrm{TB}$ is $1.5 \mathrm{~K}$ at elevations between 30 and $90^{\circ}$ for the widest bandwidth for the mid-latitude summer sounding (Fig. 8). This, for example, will lead the retrieval algorithms to slightly over-estimate the temperature at low altitudes for both mid-latitude soundings. The largest error in the retrieved low-level temperature is an over-estimation of $0.1 \mathrm{~K}$ for the largest bandwidth (Fig. 9). Starting at $6^{\circ}$ elevation, the opposite effect is observed to the left of the over-estimation. The area of underestimation widens as the elevation increases. This underestimation is associated to the negative curvature of the TB spectrum (Fig. 7). This inflection is caused by the absorption reaching the values associated to the edge of the absorption peak at the most transparent frequencies and are 


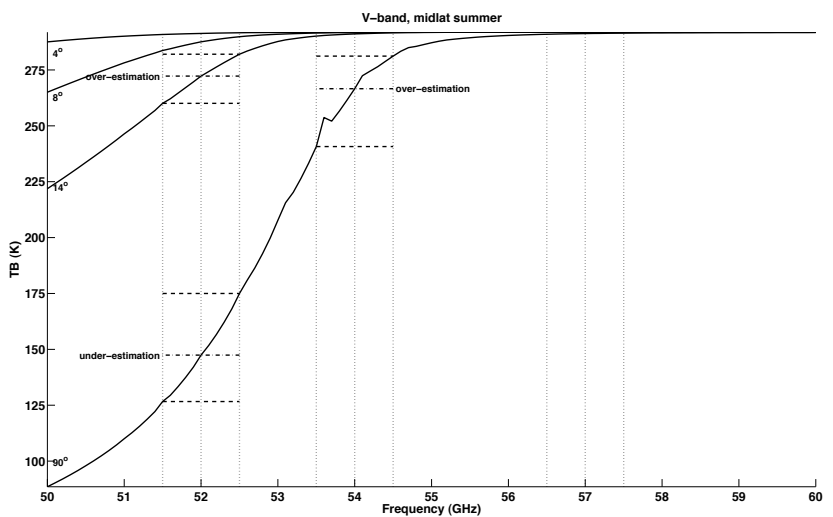

Fig. 7. Explanation of over and under estimations that cause the bandwidth errors, which are linked to the curvature of the TB vs. frequency curve in V-band for the mid-latitude summer sounding. The vertical dotted lines represent the $1 \mathrm{GHz}$ bandwidth (centre line is centre frequency). The short horizontal dashed lines are used to locate the intersection of the extremities of the bandwidth and the dashed dot line locates the centre frequency on the TB curve. These additional lines help to visually see that the over-estimation and under-estimation errors are linked to the curvature of the TB curve.

linked to higher altitudes in the atmosphere. Therefore, this will tend to under-estimate the temperature at mid-level altitudes in the atmosphere. The maximum value of the underestimation in TB is $-0.6 \mathrm{~K}$ at elevations between 20 and $30^{\circ}$ for the widest bandwidth again for the mid-latitude summer sounding (Fig. 8). The largest error in the retrieved mid-level $(4 \mathrm{~km})$ temperature is an under-estimation of $-1.8 \mathrm{~K}$ for the largest bandwidth for both mid-latitude soundings (Fig. 9).

In the case that the receiver bandwidth is small enough, the effects of the individual oxygen absorption peaks will become apparent. This is indicated by the presence of striations at elevations above $4^{\circ}$. The striations are seen as alternating over-estimations in $\mathrm{TB}$, with maximum around $7.9 \mathrm{~K}$, and under-estimations, with minima around $-2 \mathrm{~K}$, at an elevation of $90^{\circ}$ for the widest bandwidth using the mid-latitude summer sounding (Fig. 8). The striations are not so noticeable at angles below $6^{\circ}$, because of the saturation of the low elevation angles that mask most of them. Each of the oxygen absorption peaks have areas of over-estimation and underestimation associated with the absorption peak as seen with the K-band's single peak. The choice of the resolution is most challenging for the $\mathrm{V}$-band due to these multiple absorption peaks. In order to take into account the individual effect of each line, the resolution would need to be much finer than the minimum of $100 \mathrm{MHz}$ used here. Most radiometers do not resolve every individual line. Therefore, it is important that the radiometer's centre frequencies and bandwidth are chosen to be between these oxygen peaks, as is done with the HATPRO instrument (Rose et al., 2005) (Fig. 10). The individual peaks will have an effect on the errors caused by the radiometers
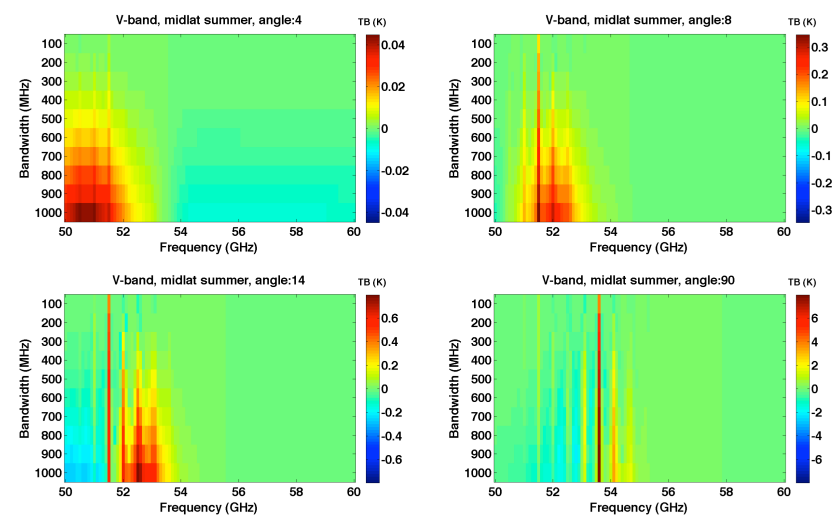

Fig. 8. The errors associated to the channel bandwidth effect in differential TB for V-band frequencies using the mid-latitude summer atmospheric profile. The TB differences are defined as the TB calculated from a forward model without bandwidth minus the TB calculated from a forward model with bandwidth.

bandwidth in V-band. The magnitude of the error will depend on the size of the bandwidth considered. The peaks can be either averaged out at large bandwidth or detected individually at narrower ones. Here, the bandwidths are calculated for each frequency independently and are plotted. It is for this reason that the striations are not smeared at wider bandwidths. These effects are not seen in K-band as it is a single peak, nor are they seen in W-band, which is a window region in the absorption spectrum. The only small difference between the soundings is the magnitude of the errors caused by the bandwidth approximation. The maximum errors in TB are of $7 \mathrm{~K}$ for the over-estimation and $-2 \mathrm{~K}$ for the underestimation in the mid-latitude winter sounding at an elevation of $90^{\circ}$ for the $1 \mathrm{GHz}$ bandwidth. In the tropical sounding, the over-estimation is 7 and $-2 \mathrm{~K}$ for the under-estimation. For the subarctic summer sounding, the over-estimation is $8.5 \mathrm{~K}$ and under-estimation $-2.5 \mathrm{~K}$. This shows a difference of error in TB on the order of $1.5 \mathrm{~K}$ for the over-estimation between these soundings and a difference on the order of $0.5 \mathrm{~K}$ are seen in the under-estimation errors.

\subsubsection{W-band simulations}

In W-band, the TB frequency curvature at any given angle is highly linear (no absorption peaks) due to the fact that this frequency band is an atmospheric window region (Fig. 3). Therefore, the channel bandwidth frequencies errors are negligible. Window regions are not interesting for radiometric profiling, because some variation of absorption with frequency is needed to be able to obtain height-resolved information. Thus, only integrated amounts will be possible as the slope does not seem strong enough for sounding (ranging) techniques. This band is the most sensitive to cloud liquid water of the three bands examined here because cloud absorption increases as the square of the frequency (Fig. 3). 

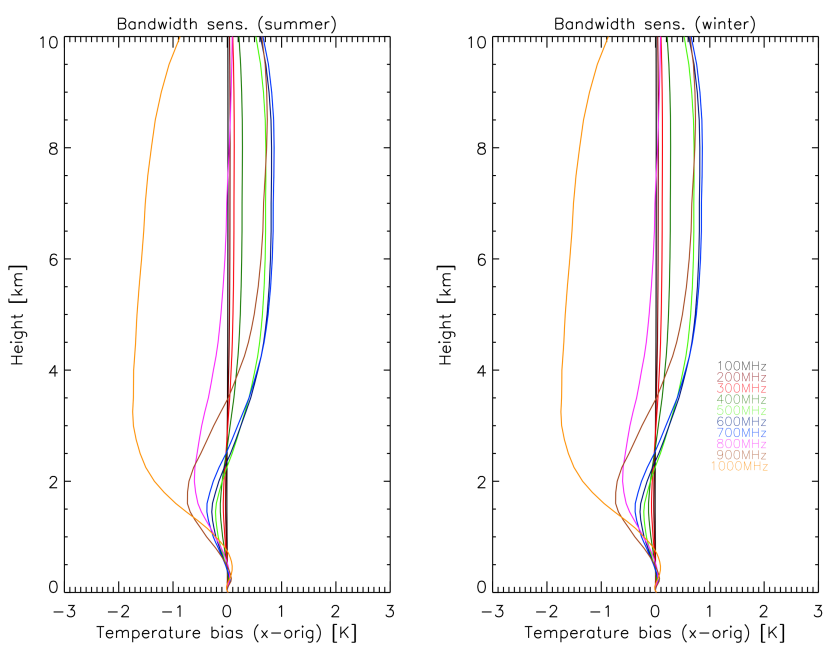

Fig. 9. The error in the retrieved temperature caused by the errors in TB by not taking into account channel bandwidth for different levels in the atmosphere. The errors are shown for both the midlatitude summer (right) and the mid-latitude winter (left) soundings for different bandwidths (colour scale).

Thus, it is well suitable to provide information on low LWP in the atmosphere (Crewell and Löhnert, 2003).

\subsubsection{General comments on bandwidth biases}

The question of the channel bandwidth is particularly important for radar-radiometer synergy, because of the link between integration time and bandwidth. The theoretical precision of a radiometer is given by

$\Delta T=\frac{\gamma\left(T_{\mathrm{N}}+T_{\mathrm{A}}\right)}{\sqrt{\beta \Delta t}}$,

where $\gamma$ is a constant that can be from 1 to 2 depending on the radiometer design, $T_{\mathrm{N}}$ is the instrument's noise temperature (here $700 \mathrm{~K}$ ), $T_{\mathrm{A}}$ is the measured TB (here $300 \mathrm{~K}$ ), $\beta$ is the channel bandwidth, and $\Delta t$ is the measurement integration time (Ulaby et al., 1981). The noise temperature is an instrument dependent constant. The radiometer and atmospheric noises causes a random error around the true measurement value unlike the other errors mentioned in this paper, which are biases. From Eq. (17), it is apparent that the product of receiver bandwidth and integration time controls the radiometer precision. If the radar and radiometer systems are on the same scanner and the scan rate is determined by the radar scan strategy, the radiometer integration time will be very short compared to traditional ground-based radiometer systems. Thus, in order to maintain or improve the radiometer sensitivity under such operational constrains, it is necessary to increase the receiver bandwidth. For a radiometer with a bandwidth of $100 \mathrm{MHz}$ and integration time of $1 \mathrm{~s}$, the sensitivity will be $0.1 \mathrm{~K}$ for a stable total power radiometer $(\gamma=1)$ and $0.2 \mathrm{~K}$ for a Dicke switch radiometer $(\gamma=2)$, while at radar integration times $(1 / 30 \mathrm{~s})$ it will be

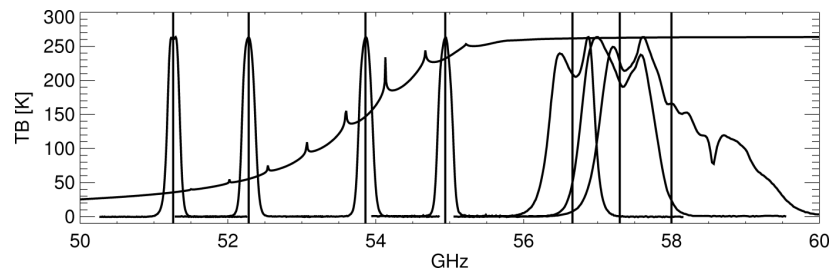

Fig. 10. The oxygen absorption complex at V-band notice individual absorption peaks that are resolved. Also plotted are the HATPRO radiometer V-band channels and their respective bandwidths. The TB spectrum plotted here was made using a sounding from RHUBIC-II in Chile (5322 $\mathrm{m}$ above m.s.l.) (G. Maschwitz, personal communication, June 2012).

of $0.6 \mathrm{~K}$ for the total power radiometer and $1.1 \mathrm{~K}$ for the Dicke switch radiometer. But if the bandwidth is increased to $1 \mathrm{GHz}$, it will be $0.2 \mathrm{~K}$ for the total power radiometer and $0.3 \mathrm{~K}$ for the Dicke switch. A worst-case scenario for the radiometer would be a fast scanning radar. An example of the fastest scans done by the USA radar network are scans at 12 s/rotation (OFCM, 2006). In this case, it can be found that the bandwidth needed to keep the radiometer precision around $0.5 \mathrm{~K}$ the bandwidth should be $120 \mathrm{MHz}$ for the total power radiometer and $480 \mathrm{MHz}$ for the Dicke switch radiometer. A better scenario, again in the point-of-view of the radiometer, would be a slow scanning radar. The slowest scan rate of the USA radars is 89 s/rotation (OFCM, 2006). In this case, the bandwidth needed to have a $0.5 \mathrm{~K}$ precision is only of $16 \mathrm{MHz}$ for the total power radiometer and $65 \mathrm{MHz}$ for Dicke switch radiometer. As noted in this example, a narrow receiver bandwidth will lead to larger noise in the measurement if the integration time does not change. This will cause more random errors in the retrieval algorithm. The impact of the increase of noise following the use of a narrow bandwidth on the retrieval will not be quantified in this paper. On the other hand, wide bandwidths are more susceptible to be affected by radio frequency interference. This is a growing problem with the frequency allocation to active radio frequency sources that are increasingly encroaching the radiometric radio frequency bands.

\subsection{Antenna beam width effect:}

In the previous section, all bandwidths could reasonably be considered for all elevation angles and all frequencies. This is not necessarily the case for the beam width effects. At $\mathrm{K}$-band, there are radiometers that have a $10^{\circ}$ beam width, but these radiometers are generally not used to scan at low elevation angles. In other cases, such as V-band and Wband, radiometers seldom have beam width larger than $3^{\circ}$. The results shown in this section will reflect these considerations: the errors only will be mentioned for beam width smaller than $4^{\circ} \mathrm{HPFW}$ in K-band and $3^{\circ} \mathrm{HPFW}$ in V-band and W-band. 

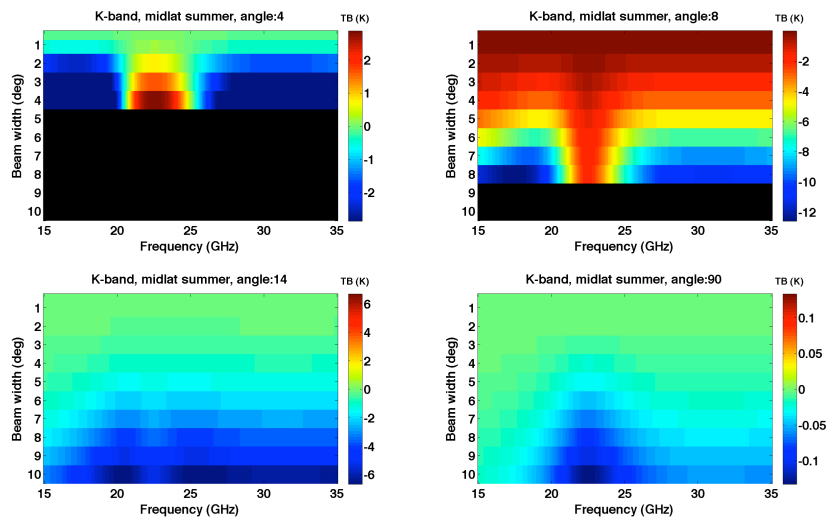

Fig. 11. The errors associated to the antenna beam width effect in differential TB for K-band frequencies using the mid-latitude summer atmospheric profile. The TB differences are defined as the TB calculated from a forward model without beam width minus the TB calculated from a forward model with beam width. Black area at elevations $4^{\circ}$ and $8^{\circ}$ are when the beam at least partially hits the ground.

\subsubsection{K-band simulations}

In K-band, the errors introduced by the antenna beam width approximation can be large, especially at low elevation angles, compared to those caused by the channel bandwidth approximation. The errors in over-estimation are of $0.5 \mathrm{~K}$ (opacity 1 ) at an elevation of $2^{\circ}$ for the $0.5^{\circ}$ beam width in the mid-latitude summer sounding. The under-estimation is of $-5 \mathrm{~K}$ (opacity 0.93 ) at an elevation of $6^{\circ}$ for the $4^{\circ}$ beam width (Fig. 11). At elevation angles below $8^{\circ}$, the over-estimation errors are present around the peak, which is not the case with higher elevation angles where only underestimation is present (Fig. 11). At these elevations, the frequencies at absorption peak are associated to a positive curvature of the TB dependency with angle, leading to an overestimation of TB, because they are optically thick and near saturation (Fig. 12). The frequencies at the wing of the peak are more transparent and, thus, are associated to the negative curvature of the TB dependency with angle leading to an under-estimation of TB. At elevations above $8^{\circ}$, the frequencies are all somewhat transparent to the atmosphere as such they have a negative curvature. Above $20^{\circ}$ elevation, the opaque absorption peak is now linked to the larger underestimation values and the transparent wings to area of smaller values. At these elevations, the transparent frequencies show little curvature, while the less transparent frequencies still have some negative curvature affecting them (Fig. 12). The magnitude of the errors decreases with increasing elevation angle to become negligible for zenith pointing instruments. This is expected since the difference of including off-zenith measurements in the beam width is less important than including the more strongly emitting lower angles at low elevation. Unlike the bandwidth errors, the beam width errors are

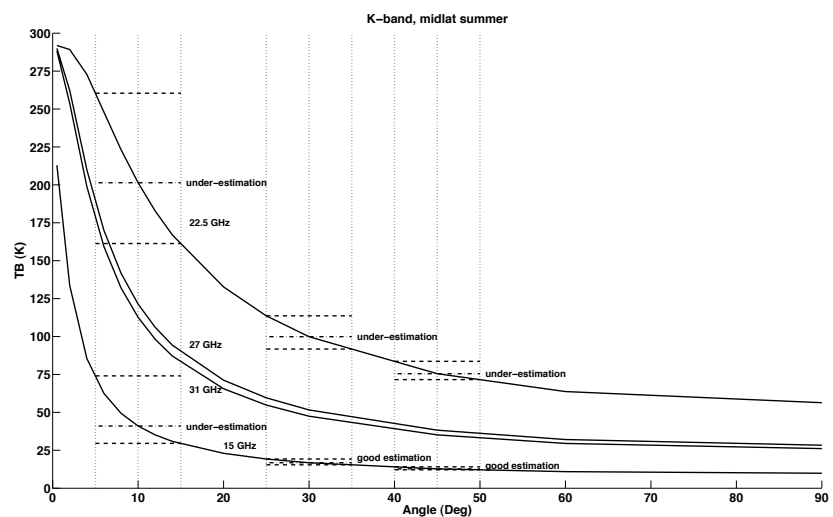

Fig. 12. Explanation of over and under estimations that cause the beam width errors, which are linked to the curvature of the TB vs. angle curve in K-band for the mid-latitude summer sounding. The vertical dotted lines represent the $10^{\circ}$ beam width (centre line is centre angle). The short horizontal dashed lines are used to locate the intersection of the extremities of the beam width and the dashed dot line locates the centre angle on the TB curve. These additional lines help to visually see that the over-estimation and underestimation errors are linked to the curvature of the TB curve.

sounding dependent. The magnitude of the errors are different in mid-latitude winter: the bias errors range from a $4.5 \mathrm{~K}$ under-estimation (opacity 0.93 ) at $6^{\circ}$ elevation for the $4^{\circ}$ beam width to no error (opacity 1.00 ) at $2^{\circ}$ elevation for the $0.5^{\circ}$ beam width. In the subarctic sounding, over-estimation is $0.5 \mathrm{~K}$ (opacity 1.03 ) at $2^{\circ}$ elevation and $1^{\circ}$ beam width, while the under-estimation is $-5 \mathrm{~K}$ (opacity 0.93 ) at $6^{\circ}$ elevation for the $4^{\circ}$ beam width. In the tropical sounding, the over-estimation is $2 \mathrm{~K}$ (opacity 1.08 ) at $4^{\circ}$ elevation for a $3^{\circ}$ beam width, while the under-estimation is of $-2 \mathrm{~K}$ (opacity 0.98 ) at $10^{\circ}$ elevation for the $4^{\circ}$ beam width. Here also, the areas of over-estimation and under-estimation errors cause a change in the TB dependency with angle shape, which has an impact on the retrieval's solutions. The errors in beam width have a larger impact on the retrieved parameters IWV and LWP (zenith corrected) than those seen with the bandwidth errors. For IWV, the largest errors occur at the $4^{\circ}$ beam width and for the lowest elevation angles $\left(10^{\circ}\right)$ where, for example, errors of $0.3 \mathrm{~kg} \mathrm{~m}^{-2}$ are seen using the winter sounding and $0.35 \mathrm{~kg} \mathrm{~m}^{-2}$ for the summer sounding (Fig. 6). For elevation angles of $30^{\circ}$, the errors at these beam width drop to $0.1 \mathrm{~kg} \mathrm{~m}^{-2}$ for summer and $0.03 \mathrm{~kg} \mathrm{~m}^{-2}$ in winter. For LWP, the summer sounding has more important errors, $1 \mathrm{~g} \mathrm{~m}^{-2}$ at $10^{\circ}$ elevation for $4^{\circ}$ beam width, than the winter sounding, where the error drops to below $1 \mathrm{~g} \mathrm{~m}^{-2}$ for the same elevation and beam width. The errors in LWP drop to below $1 \mathrm{~g} \mathrm{~m}^{-2}$ above $30^{\circ}$ elevation for all beam widths. 


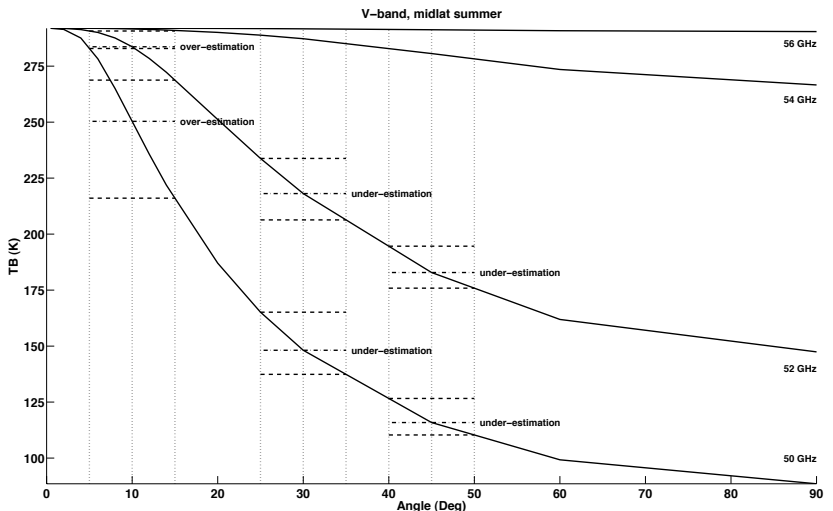

Fig. 13. Explanation of over and under estimations that cause the beam width errors, which are linked to the curvature of the TB vs. angle curve in V-band for the mid-latitude summer sounding. The vertical dotted lines represent the $10^{\circ}$ beam width (centre line is centre angle). The short horizontal dashed lines are used to locate the intersection of the extremities of the beam width and the dashed dot line locates the centre angle on the TB curve. These additional lines help to visually see that the over-estimation and underestimation errors are linked to the curvature of the TB curve.

\subsubsection{V-band simulations}

The errors related to the antenna pattern have similar magnitude to those associated with the channel bandwidth outside of the peak regions. The simulations indicate that at frequencies above $55 \mathrm{GHz}$, the brightness temperatures at these wavelengths are saturated and, therefore, no errors due to the antenna pattern are present (Fig. 13). The maximum values are of $1.1 \mathrm{~K}$ over-estimation at the $4^{\circ}$ elevation angle and an under-estimation of $-0.2 \mathrm{~K}$ at a $20^{\circ}$ elevation angle, both for the $3^{\circ}$ beam width. At elevations below $10^{\circ}$, an area of over-estimation occurs at the most transparent frequencies $(50-52 \mathrm{GHz})$ and is linked to the positive curvature of the TB curve (Fig. 14). This curvature is caused by the frequencies being transparent enough to be affected by the beam width and by the fact that, as the elevation angles get higher, the atmosphere becomes less opaque. At low elevation angles, even the electromagnetic waves at the most transparent frequencies do not propagate far through the atmosphere. Therefore, at the low elevation angles, the low altitude atmospheric temperature will tend to be over-estimated. Between elevation angles of 12 and $30^{\circ}$, an area of under-estimation appears to the left of the area of over-estimation (Fig. 14). At elevations above $45^{\circ}$, the area of over-estimation disappears completely and the area of under-estimation widens to include all frequencies below $55 \mathrm{GHz}$ (Fig. 14). The errors become smaller with increasing elevation angle. The largest error in TB at these elevations is of $-0.1 \mathrm{~K}$ for the $3^{\circ}$ beam width at $45^{\circ}$. The retrieval shows an over-estimation of less than $0.1 \mathrm{~K}$ for the $3^{\circ}$ beam width at mid-level in the atmosphere in both soundings (Fig. 15). The errors in the tem-
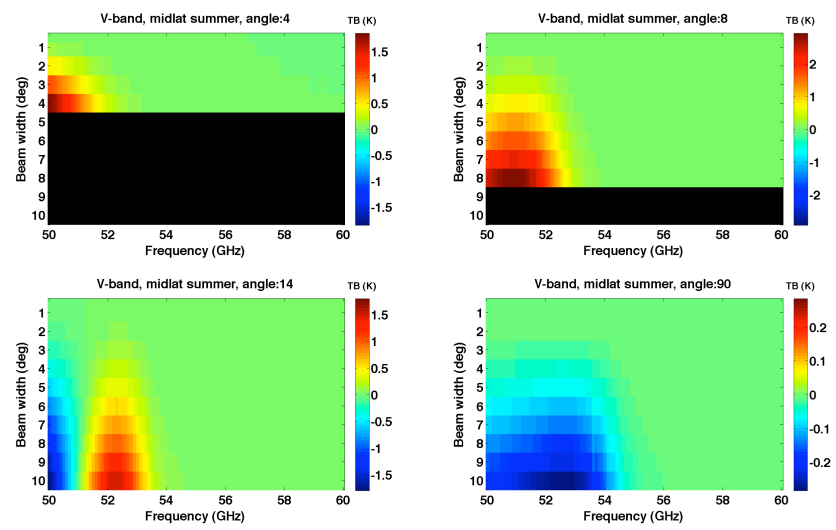

Fig. 14. The errors associated to the antenna beam width effect in differential TB for V-band frequencies using the mid-latitude summer atmospheric profile. The TB differences are defined as the TB calculated from a forward model without beam width minus the TB calculated from a forward model with beam width. Black area at elevations $4^{\circ}$ and $8^{\circ}$ are when the beam at least partially hits the ground.

perature profile change shape above $6^{\circ}$ beam width. This is caused by the beam at least partially hitting the ground. The error magnitudes and the width of areas of under-estimation and over-estimations are similar in all soundings for the beam width considered. The maximum value of over-estimation in $\mathrm{TB}$ in the winter profile is of $1.2 \mathrm{~K}$ at an elevation of $4^{\circ}$ for the $3^{\circ}$ beam width and of $-0.2 \mathrm{~K}$ for the under-estimation at an elevation of $20^{\circ}$. For the subarctic sounding, the overestimation is $1.2 \mathrm{~K}$ at an elevation of $4^{\circ}$ for the $3^{\circ}$ beam width and the under-estimation is of $-0.2 \mathrm{~K}$ for the same beam width at $20^{\circ}$ elevation. The tropical sounding shows an overestimation of $1 \mathrm{~K}$ at an elevation of $4^{\circ}$ for the $3^{\circ}$ beam width and an under-estimation of $-0.2 \mathrm{~K}$ for the same beam width at $20^{\circ}$ elevation. Therefore, the effect does not seem to be sounding dependent for the beam width considered.

\subsubsection{W-band simulations}

In W-band, the effect of antenna beam width, unlike the receiver channel bandwidth, is not negligible. The errors are an over-estimation of $1.5 \mathrm{~K}$ (opacity 1.25) for a beam width of $3^{\circ}$ at an elevation of $4^{\circ}$ and an under-estimation of $-0.5 \mathrm{~K}$ (opacity 0.995 ) at an elevation of $14^{\circ}$ for the same beam width for the mid-latitude summer sounding (Fig. 16). At these elevations, the TB curve shows a positive curvature and the amount of curvature increases with increasing beam width. The positive curvature is linked to the low elevation angles being near saturation. Above $12^{\circ}$ elevation, there is a gradient from negligible error to under-estimation at larger beam width. Here, the TB curve shows a negative curvature and the amount of curvature increases with increasing beam width. The negative curvature is linked to the higher angles passing through more transparent layers in the atmosphere. 

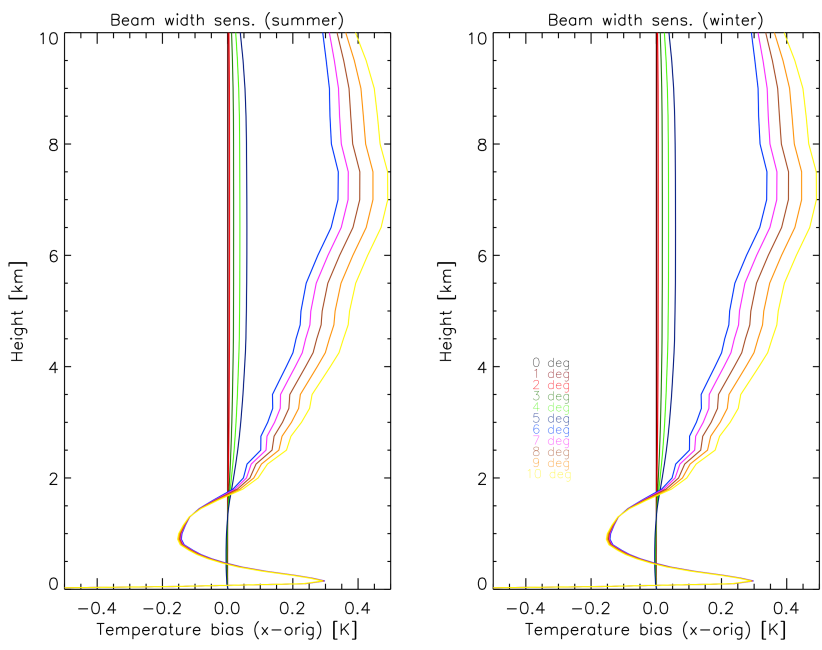

Fig. 15. The error in the retrieved temperature caused by the errors in TB by not taking into account antenna beam width for different levels in the atmosphere. The errors are shown for both the midlatitude summer (right) and the mid-latitude winter (left) soundings for different beam widths (colour scale).

At elevations above $45^{\circ}$, the errors drop below $-0.05 \mathrm{~K}$ (opacity 0.999 ) for the $3^{\circ}$ beam width, because the curvature of the TB curve is reduced. In the mid-latitude winter sounding, the over-estimation is of $0.6 \mathrm{~K}$ (opacity 1.02 ) at $2^{\circ}$ elevation for the $1^{\circ}$ beam width and the under-estimation is of $-1.5 \mathrm{~K}$ (opacity 0.985 ) at $4^{\circ}$ elevation for a $3^{\circ}$ beam width. In the subarctic summer sounding, the over-estimation is of $1.6 \mathrm{~K}$ (opacity 1.065 ) at $4^{\circ}$ elevation for a $3^{\circ}$ beam width and the under-estimation is of $-0.6 \mathrm{~K}$ (opacity 0.992 ) at $12^{\circ} \mathrm{el}-$ evation for a $3^{\circ}$ beam width. The tropical sounding shows an over-estimation of $0.7 \mathrm{~K}$ (opacity 1.05 ) at $4^{\circ}$ elevation for a $3^{\circ}$ beam width and an under-estimation of $-0.2 \mathrm{~K}$ (opacity 0.998 ) at $20^{\circ}$ elevation for a $3^{\circ}$ beam width. As mentioned previously, $\mathrm{W}$-band is very sensitive to the presence of clouds and, thus, these errors will cause the retrieval algorithm to change the LWP. Thus the retrieval might compensate the over-estimation (under-estimation) by adding (subtracting) liquid water amounts in the atmosphere if there is no other piece of information (e.g., lidar, radar or other radiometer channels such as K-band) to help locate the presence of liquid water.

\subsubsection{General comments on beam width biases}

Blahak (2008) has studied the effect of the elongation of the beam caused by averaging over several measurements while scanning. Although this was derived for radar, this effect would present in scanning radiometers measurement if the radiometer does not stare during the collection of data. In a stand-alone mode, the instrument could stop at any given angle to collect a series of measurement and then continue to the next angle as such the dwell time and elongation are not
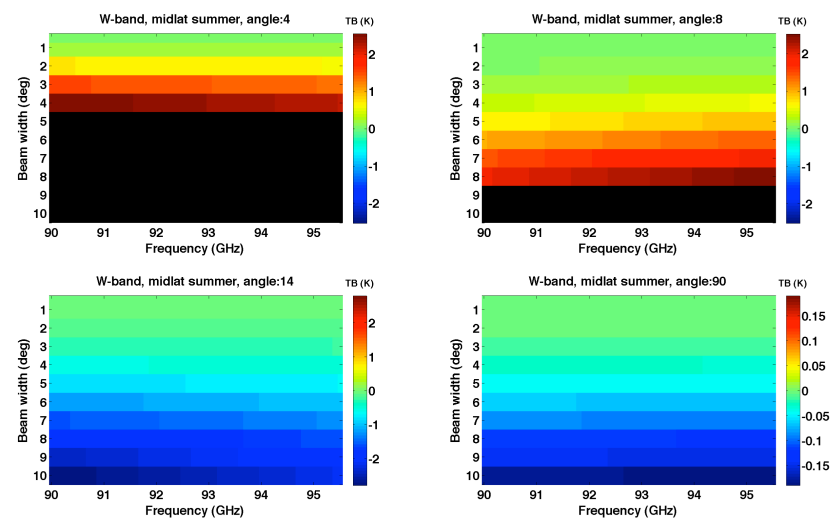

Fig. 16. The errors associated to the antenna beam width effect in differential TB for W-band frequencies using the mid-latitude summer atmospheric profile. The TB differences are defined as the TB calculated from a forward model without beam width minus the TB calculated from a forward model with beam width. Black area at elevations $4^{\circ}$ and $8^{\circ}$ are when the beam at least partially hits the ground.

an issue. However, when radiometers co-scan with radars, the dwell time required to follow the radar is very short. Thus, the radiometer must take near continuous measurements and the problem of elongation appears. Another issue is the beam matching between the instruments. It is important to note that the beam width will depend on frequency. Higher frequencies have narrower beam width. Therefore, when using instruments with different frequencies, beam matching will have to be taken into account. In the case of radar and radiometer sharing the same antenna, the radar antennas are not quite suitable for radiometric use. Radiometers require antennas with very little side lobes, so that the measurement is not contaminated by radiation incoming from different sources. This problem is more important for radiometer than for radar because the radar signal is 2-way, which reduced the side lobes by the square. The radiometer, being only 1-way, does not have this advantage.

\subsection{Refractive index effect}

The refractive index error is calculated as the difference between the TB calculated by the forward model using the full propagation (Eqs. 9 and 10) and the TB calculated by the forward model using the propagation with $4 / 3$-earth radius approximation (Eqs. 6 and 7). It is to be noted that both the beam width and the bandwidth are omitted in the refractive index calculations. The impact of the vertical gradient of the refractive index of air on the radio propagation depends on the assumed atmospheric structure. Here, climatological soundings represent an average for a certain climate zone and extreme refractive index profiles are not included. A more comprehensive study will need to use a large number of soundings capturing the variability of the vertical gradient 

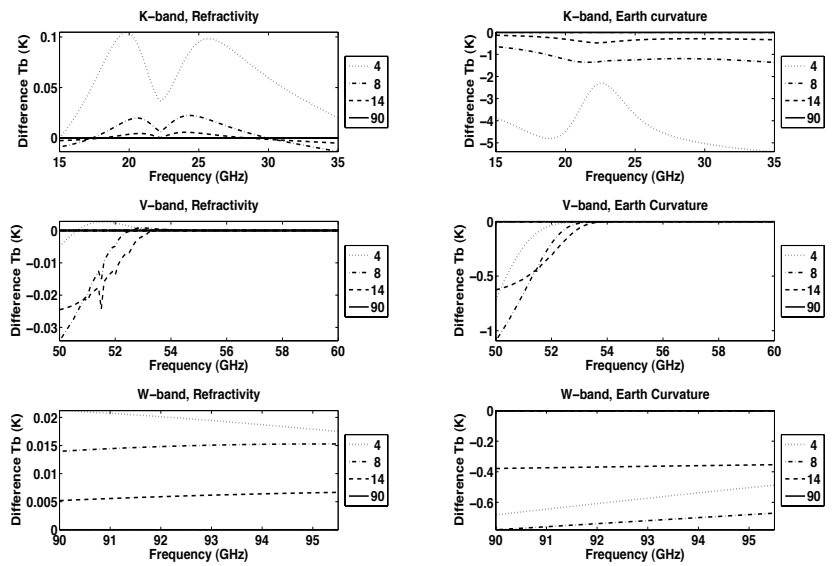

Fig. 17. The errors in TB associate to the refractivity effect on the left column and the Earth curvature effect on the right column at all frequencies for the mid-latitude summer profile in TB differences. The top plots show the results for K-band, the middle ones are Vband, and the bottom ones are W-band. In all plots, the dashed line is $4^{\circ}$ elevation, dotted line is $8^{\circ}$, dash dot line is $14^{\circ}$, and the full line is $90^{\circ}$.

of the refractive index. The propagation errors are more important at low elevations. In the case of the refractive index, the lower elevation angles are most affected because the radiation must travel longer through a thicker part of the atmosphere and will be bent more, while at $90^{\circ}$ (zenith) there will be no effect. The main quantities affecting the change of refractive index are pressure, temperature and water vapour.

The simulated errors at K-band are larger than the errors of the other frequency bands studied. The saturation of the $\mathrm{V}$-band and $\mathrm{W}$-band frequencies causes the TB to be less sensitive to the change of the beam altitude due to the refractive index. Thus, the errors at these frequencies are negligible. The errors in K-band are over-estimations with the warm soundings and under-estimations with the cold soundings (Fig. 17). The errors are of $0.5 \mathrm{~K}$ at $2^{\circ}$ elevation in mid-latitude summer, $-1 \mathrm{~K}$ in mid-latitude winter, $0.9 \mathrm{~K}$ in tropical and $-0.4 \mathrm{~K}$ in subarctic at the same elevation angle and are larger at lower elevation angles (in subarctic the sign changes at lower elevation). The effect is more important at low frequencies where the atmosphere is more transparent and the waves propagate further. At elevations above $8^{\circ}$, the effects are negligible for all frequency bands, as found by HW00 for K-band.

\subsection{Earth curvature effect}

The Earth curvature errors are calculated as the difference between the TB calculated by the forward model using propagation with 4/3 Earth radius (Eqs. 6 and 7), which includes the Earth curvature, and TB calculated by the forward model using propagation without Earth curvature (Eq. 5). It is to be noted that, here again, both the beam width and
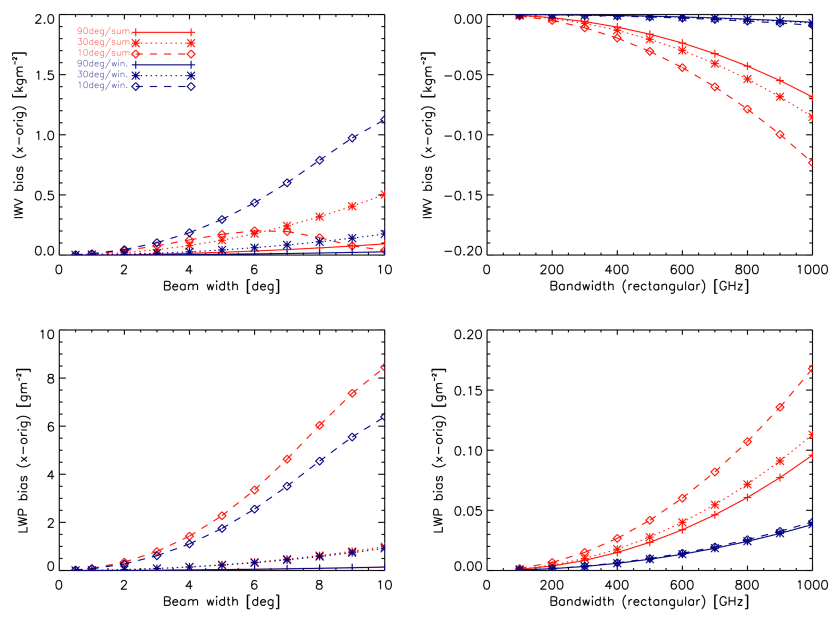

Fig. 18. The error in the retrieved IWV (in $\mathrm{kg} \mathrm{m}^{-2}$ ) and LWP (in $\mathrm{g} \mathrm{m}^{-2}$ ) zenith corrected caused by the errors in TB by not taking into account antenna beam width (right) or bandwidth (left). The errors are shown for both the mid-latitude summer (red) and the mid-latitude winter cloudy soundings (blue) for elevation angles $10^{\circ}$ (dash square), $30^{\circ}$ (dot star) and $90^{\circ}$ (line + ).

the bandwidth are omitted in the calculations. The effect of Earth curvature on the radiometer measurement causes under-estimation at all frequencies. The amount of underestimation depends on the frequency band with K-band having the largest errors and V-band the smallest. Since the Kband frequencies are not saturated, the effect caused by the change of height of the beam due to the Earth curvature will affect the measurement of TB (Fig. 17). This effect will cause smaller changes in the beam height at frequencies that are near saturation, such as V-band and W-band. This effect is also elevation angle dependent. At high elevation angles, whether the Earth is spherical or flat changes very little the height at which the beam is pointing. At low elevation angles, the Earth curvature increases the height above ground at which the instrument points. Thus, the effect is most pronounced at low elevation angles, less than $6^{\circ}$, with the lowest angle being the most strongly affected.

For K-band, the lowest elevation angles seem to show a larger effect on the low-frequency wing. Above $4^{\circ}$ elevation, the effect becomes more symmetrical for both wings. The absorption peak being saturated shows little effect. Above $10^{\circ}$ elevation, the maximum shifts from the wings to the peak, but the errors are less than at lower elevation angles. The errors are somewhat larger in the winter sounding. This is cause by the frequencies being less saturated in the colder drier winter sounding. The error is $-5.4 \mathrm{~K}$ at an elevation of $4^{\circ}$ in mid-latitude summer, $-6.1 \mathrm{~K}$ in mid-latitude winter, $-4.6 \mathrm{~K}$ in tropical and $-5.9 \mathrm{~K}$ in subarctic at the same elevation and again are larger at lower elevations. HW00 found that the effects are still relatively important at higher elevation angles. They also offer a correction to minimise this effect. The under-estimation errors will cause an under-estimation 
Table 3. Summary of the range of biases in clear air for elevation angles above $4^{\circ}$ in TB (in K) associated to each effect (bandwidth (100$1000 \mathrm{MHz})$, beam width $\left(0.5-10^{\circ}\right)$, refractivity, and Earth curvature) for each set of frequencies and each sounding. Entries with long dashes represent values that are below any instrument measurement capability.

\begin{tabular}{|c|c|c|c|c|c|c|c|c|}
\hline & \multicolumn{2}{|c|}{$\begin{array}{l}\text { Mid-latitude } \\
\text { summer }\end{array}$} & \multicolumn{2}{|c|}{$\begin{array}{l}\text { Mid-latitude } \\
\text { winter }\end{array}$} & \multicolumn{2}{|c|}{$\begin{array}{l}\text { Subarctic } \\
\text { summer }\end{array}$} & \multicolumn{2}{|c|}{$\begin{array}{l}\text { Tropical } \\
\text { summer }\end{array}$} \\
\hline & Max & Min & $\operatorname{Max}$ & Min & Max & Min & Max & Min \\
\hline Bandwidth K-band & 1.5 & -0.8 & 1.4 & -0.6 & 1.4 & -0.7 & 1.5 & -0.7 \\
\hline Bandwidth V-Band (peaks) & 8 & -2 & 7 & -2 & 8.5 & -2.5 & 7 & -2 \\
\hline Bandwidth W-Band & - & - & - & - & - & - & - & - \\
\hline Beam width K-band ( $\left.4^{\circ} \mathrm{HPFW}\right)$ & 0.5 & -5 & 0 & -4.5 & 0.5 & -5 & 2 & -2 \\
\hline Beam width V-band $\left(3^{\circ} \mathrm{HPFW}\right)$ & 1.1 & -0.2 & 1.2 & -0.2 & 1.2 & -0.2 & 1 & -0.2 \\
\hline Beam width W-band $\left(3^{\circ} \mathrm{HPFW}\right)$ & 1.5 & -0.5 & 0.6 & -1.5 & 1.6 & -0.6 & 0.7 & -0.2 \\
\hline Refractivity K-band & 0.5 & 0 & 0 & -1 & 0.25 & -0.4 & 0.9 & 0 \\
\hline Refractivity V-band & - & - & - & - & - & - & - & - \\
\hline Refractivity W-band & - & - & - & - & - & - & - & - \\
\hline Curvature K-band & - & -5.4 & - & -6.1 & - & -5.9 & - & -4.6 \\
\hline Curvature V-band & - & -1.1 & - & -1.3 & - & -1.2 & - & -0.9 \\
\hline Curvature W-band & - & -0.7 & - & -5.4 & - & -1.6 & - & -0.9 \\
\hline
\end{tabular}

of IWV and LWP in the retrievals. For V-band, there is also an under-estimation. At these frequencies, two effects come into play the first, and most important, is saturation. This is the reason why the lower elevation angles to show no change. The more opaque frequencies $(>53 \mathrm{GHz})$ are saturated and an apparent change in elevation angles will have little effect. For the more transparent frequencies, the effect of the change of altitude of the beam caused by the Earth curvature will be more important. When not saturated, this effect is more important at elevation angles up to $30^{\circ}$ in elevation and no changes are seen at zenith. The errors are very similar between the soundings. The maximum error in mid-latitude summer is $-1.1 \mathrm{~K}$ between 6 and $8^{\circ}$ in elevation, $-1.3 \mathrm{~K}$ in mid-latitude winter, $-0.9 \mathrm{~K}$ in tropical, and $-1.2 \mathrm{~K}$ in subarctic at the same elevations. The retrieval will cause an under-estimation of the temperature profile at all levels in the atmosphere. As with the V-band, the W-band also has the saturation and the Earth curvature effect competing with each other. At very low elevations angles, the saturation effects are dominant. At less opaque elevation angles, it is the height difference caused by the Earth curvature that is dominant up to a certain point where, at higher elevation angles, the effect is too small. The most affected angles are found at elevation angles up to $30^{\circ}$. Here again, the errors are more important in the winter sounding than in the summer one. The maximum errors are $-0.7 \mathrm{~K}$ in mid-latitude summer at elevation of $6^{\circ},-5.4 \mathrm{~K}$ at $2^{\circ}$ in the mid-latitude winter, $-0.9 \mathrm{~K}$ at $8^{\circ}$ in tropical and $-1.6 \mathrm{~K}$ at $4^{\circ}$ in subarctic. These errors will also cause the retrieval to under-estimate the LWP.

\subsection{Effect of clouds on biases}

As mentioned before, we added a slab cloud to the different soundings and did the same analysis as was done with the previous clear air cases. The biases caused by omitting the bandwidth are not affected by the presence of this cloud. For the bandwidths experiment, the results remain very similar to those found in the clear air case. This is due to the fact that the addition of the cloud did not change the curvature of the TB as a function of frequency. On the other hand, most of the beam width biases are reduced except for the K-band that shows little change compared to the clear air. This is because the cloud raised all TB preferentially at low opacity bands and at high frequencies. This reduces all curvatures and, hence, reduces the biases associated with them. The effect of both the refractive index and the Earth curvature were also reduced. In both soundings used as examples for the retrieval, the LWP increases, which is expected because of the presence of cloud (Fig. 18). The effect of beam width for clouds between 0 and $300 \mathrm{~g} \mathrm{~m}^{-2}$ will show values of LWP in between these values. As mentioned before, the LWP retrieval was also done for clear air soundings (Fig. 6). The LWP non-zero values found in the case of clear air show that omitting of the beam width or bandwidth can lead to false cloud detection in a retrieval algorithm. The clouds do not affect the temperature profile retrieval.

\section{Summary}

This study investigates the bias errors introduced to scanning radiometer measurements related to the instrument's receiver bandwidth (100-1000 MHz), antenna beam width, $\left(0.5-10^{\circ}\right)$, atmospheric refraction and Earth curvature (Table 2). The causes of the errors were determined and their effects on the retrieved atmospheric parameters integrated water vapour (IWV), liquid water path (LWP) and temperature profile were also examined for three frequencies bands. The 
Table 4. Summary of retrieval errors associated to the different effects (bandwidth $(100-1000 \mathrm{MHz})$, beam width $\left(0.5-10^{\circ}\right)$ ) for each retrieval parameter IWV $\left(\mathrm{kg} \mathrm{m}^{-2}\right)$, LWP $\left(\mathrm{g} \mathrm{m}^{-2}\right)$ and temperature $\left.(\mathrm{K})\right)$ for both mid-latitude soundings. Entries with long dashes represent values that are below any instrument measurement capability. The IWV and LWP values are mapped to zenith, while the temperature is not.

\begin{tabular}{lrrrrrr}
\hline & \multicolumn{2}{c}{ Mid-latitude summer } & & \multicolumn{2}{c}{ Mid-latitude winter } \\
\cline { 2 - 3 } \cline { 6 - 7 } & Maximum & Minimum & & Maximum & Minimum \\
\hline IWV bandwidth $\left(\mathrm{kg} \mathrm{m}^{-2}\right)$ & 0 & -0.12 & & 0 & -0.01 \\
IWV beam width $\left(\mathrm{kg} \mathrm{m}^{-2}\right)$ & 0.95 & 0 & & 1.2 & 0 \\
LWP bandwidth $\left(\mathrm{g} \mathrm{m}^{-2}\right)$ & - & 0 & & - & 0 \\
LWP beam width $\left(\mathrm{g} \mathrm{m}^{-2}\right)$ & 5.5 & 0 & & 1.5 & 0 \\
$T$ bandwidth $(\mathrm{K})$ & 0.7 & -1.8 & & 0.7 & -1.8 \\
$T$ beam width $(\mathrm{K})$ & 0.1 & - & & 0.1 & - \\
\hline
\end{tabular}

errors were defined as differences in brightness temperature (TB) between the forward model approximations that does not account for the instruments characteristics, $\mathrm{TB}_{\text {assumption }}$ (or in the case of the refractivity and Earth curvature study the more complex formulation) and a forward model that would have all these characteristics included, $\mathrm{TB}_{\text {reality }}$ (the simplest form). Depending on the curvature of the TB curve, positive or negative $\mathrm{TB}_{\text {error }}$ are found. Areas with positive curvature will cause $\mathrm{TB}_{\text {assumption }}$ to be over-estimated com-

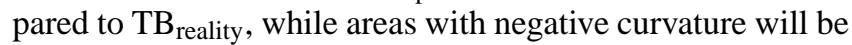
responsible for the under-estimation of $\mathrm{TB}_{\text {assumption with re- }}$ spect to $\mathrm{TB}_{\text {reality. The errors calculations were done for four }}$ climatological soundings: mid-latitude summer and winter, tropical and subarctic summer. The soundings are clear air, but a $1 \mathrm{~km}$ deep cloud with LWP $300 \mathrm{~g} \mathrm{~m}^{-2}$ was added to them as well.

At K-band $(15-35 \mathrm{GHz})$, the effect of the bandwidth is smaller than the beam width effect. The largest errors in bandwidth $(1.5 \mathrm{~K})$ were associated with an over-estimation around the absorption peak in mid-latitude summer and tropical cases (Table 3). The beam width effect yields larger errors. The under-estimation linked to the absorption peak has errors of $-5 \mathrm{~K}$ in the mid-latitude and subarctic summer cases, while the over-estimation is around $2 \mathrm{~K}$ in the tropical case (Table 3). These large errors are found at low elevation angles, below $10^{\circ}$. This leads to errors in the retrieved integrated atmospheric quantities of IWV and LWP that are much larger in beam width (IWV $0.35 \mathrm{~kg} \mathrm{~m}^{-2}$ and LWP $1 \mathrm{~g} \mathrm{~m}^{-2}$ ) than in bandwidth (IWV $-0.12 \mathrm{~kg} \mathrm{~m}^{-2}$ and LWP $<1 \mathrm{~g} \mathrm{~m}^{-2}$ ) just as with the TB errors (Table 4). The biases caused by the beam width and bandwidth approximation can lead the retrieval to interpret that there is a cloud even in clear air. As the elevation angles increases, these errors decrease until they become negligible above $45^{\circ}$. The main challenges in the V-band $(50-60 \mathrm{GHz})$ are the errors in bandwidth caused by the absorption peaks making up the oxygen complex. These absorption peaks cause under-estimation errors and over-estimation errors depending on the TB spectrum's curvature. The under-estimation can be as large as $-2.5 \mathrm{~K}$ and the over-estimation range around $8.5 \mathrm{~K}$ for the subarctic case (Table 3). Therefore, it is important to choose the V-band frequencies between the absorption peaks to reduce the errors. If the frequencies are placed between these absorption peaks and are used at low elevation angles, the errors in bandwidth are reduced. The errors on the retrieved temperature profile caused by the errors in TB by the channel bandwidth are negligible at low levels in the atmosphere and become negative $(-1.8 \mathrm{~K})$ at mid-levels in the atmosphere (Table 4). The beam width errors are larger at low elevation angles, where an over-estimation of $1.2 \mathrm{~K}$ is found at the low frequencies (Table 3). At elevations above $20^{\circ}$, the errors become under-estimation at these frequencies, but these errors are smaller with a maximum around $-0.2 \mathrm{~K}$. The errors on the retrieved temperature profile cause by the errors in TB by the antenna beam width are over-estimation of less than $0.1 \mathrm{~K}$ at mid-levels for beam width of $3^{\circ}$ (Table 4). In W-band (90-95 GHz), the errors related to the beam width are the most important especially at elevation angles below $14^{\circ}$. At elevation below $8^{\circ}$, the errors are over-estimations with errors such as $1.5 \mathrm{~K}$ in mid-latitude summer and $1.6 \mathrm{~K}$ in subarctic (Table 3). At higher elevations, the errors turn to under-estimation with the largest errors around $-1.5 \mathrm{~K}$ in mid-latitude winter (Table 3 ). These errors become negligible above $45^{\circ}$ in elevation. The bandwidth effects are also negligible because there is no absorption peak (Table 3). Wband frequencies are very sensitive to cloud liquid water so the errors are going to affect the LWP retrievals. For the effect of vertical gradient of the atmospheric refractive index, the K-band frequencies are the most affected $(0.9 \mathrm{~K}$ in tropical and $-1 \mathrm{~K}$ in mid-latitude winter at $4^{\circ}$ and larger at lower elevations), because it is the only frequency band that is not nearly saturated at low elevation angles (Table 3). This effect is also reduced at higher elevations angles as previously found by HW00. However, the information we can derive about this effect is limited because of the use of the climatological soundings and a climatological refractive index. The errors caused by the refractive index effects are smaller than those associated with the bandwidth effect for all frequencies. The Earth curvature yields under-estimation errors for all frequencies. This effect also has the greatest effect in 
$\mathrm{K}$-band $\left(-6.1 \mathrm{~K}\right.$ in mid-latitude winter at $4^{\circ}$ and larger at lower elevations) for the same reason as the refractive index effect (Table 3). Clouds have little effect on the biases caused by the beam width and bandwidth and reduce the effects of the refractive index and Earth curvature.

The errors of beam width and bandwidth found in this paper are bias errors caused by using the zero beam width and bandwidth approximation in the radiometric forward model. These biases indicate by how much this approximation is no longer valid and must be compensated for by using corrections. A typical measurement accuracy of brightness temperature measurements from microwave radiometers is $0.5 \mathrm{~K}$. In that context, we can consider that the largest bias errors caused by omitting either the beam width or the bandwidth that could be acceptable without the need to correct for or take into account these characteristics should ideally be less than half of the accuracy of brightness temperature measurements. For existing commercial radiometers, this occurs at elevation angles larger than $25^{\circ}$ for all frequencies for the beam width effect $\left(3^{\circ} \mathrm{HPFW}\right)$ and for bandwidths smaller than $400 \mathrm{MHz}$.

Acknowledgements. This work was funded by the Natural Science and Engineering Research Council of Canada. The authors thank their colleagues from MWRnet for discussions leading to this paper at the EG-CLIMET Special Working Group workshop in Cologne.

Edited by: D. Feist

\section{References}

Battaglia, A., Saaverdra Garfias, P., Rose, T., and Simmer, C.: Characterization of precipitating clouds by ground-based measurements with the triple-frequency polarized microwave radiometer ADMIRARI, J. Appl. Meteorol. Clim., 49, 394-414, 2010.

Bianco, L., Cimini, D., Marzano, F. S., and Ware, R.: Combining Microwave Radiometer and Wind Profiler Radar Measurements for High-Resolution Atmospheric Humidity Profiling, J. Atmos. Ocean. Tech., 22, 949-965, 2005.

Blahak, U.: An approximation to the effective beam weighting function for scanning meteorological radars with axisymmetric antenna patterns, J. Atmos. Ocean. Tech., 25, 1182-1196, 2008.

Blaskovic, M., Bow, T. C., and Rogers, R. R.: Radiometric observations during CASP, Montreal: Stormy Weather Group Scientific Report, McGill University, Montreal, Canada, 1987.

Cadeddu, M. P.: Microwave Radiometer - High Frequency Handbook, Office of Science, US Department of Energy, DOE/SCARM/TR-080, Washington, DC, USA, 2011.

Cadeddu, M. P.: Microwave Radiometer -3 channel (MWR3C) Handbook, Office of Science, US Department of Energy, DOE/SC-ARM/TR-108, Washington, DC, USA, 2012.

Cadeddu, M. P. and Turner, D. D.: Evaluation of water permittivity models from ground-based observations of cold clouds at frequencies between 23 and $170 \mathrm{GHz}$, IEEE T. Geosci. Remote, 49, 2999-3008, 2011.
Crewell, S. and Löhnert, U.: Accuracy of cloud liquid water path from ground-based microwave radiometry 2. Sensor accuracy and synergy, Radio Sci., 38, 8042, doi:10.1029/2002RS002634, 2003.

Crewell, S. and Löhnert, U.: Accuracy of Boundary layer temperature profiles retrieved with multifrequency multiangle microwave radiometry, IEEE T. Geosci. Remote, 45, 2195-2201, 2007.

Crewell, S., Czekala, H., Löhnert, U., Simmer, C., Rose, T., Zimmermann, R., and Zimmermann, R.: Microwave Radiometer for Cloud Carthography: A 22-channel ground-based microwave radiometer for atmospheric research, Radio Sci., 36, 621-638, 2001.

Doviak, R. J. and Zrnic, D. S.: Doppler radar and weather observations, 2nd Edn., Dover publications Inc., Mineola, NY, USA, 2006.

Frisch, A. S., Fairall, C. W., and Snider, J. B.: Measurement of stratus cloud and drizzle parameters in ASTEX with a $\mathrm{K}_{\mathrm{a}}$-band Doppler radar and a microwave radiometer, J. Atmos. Sci., 52, 2788-2799, 1995.

Gaffard, C., Hewison, T., and Nash, J.: Toward the combination of active and passive remote sensors for temperature and humidity profiling, 6th International Symposium on Troposhperic Profiling, Leipzig, Germany, 14-20 June, 2003.

Gaikovich, K. P.: Inverse problems in physical diagnostics, Nova Science Publishers Inc., Hauppauge, NY, USA, 2004.

Güldner, J. and Spänkuch, D.: Results of a year-round remotely sensed integrated water vapour by ground-based microwave radiometry, J. Appl. Meteorol. Clim., 38, 981-988, 1999.

Han, Y. and Westwater, E. R.: Analysis and improvement of tipping calibration for ground-based microwave radiometers, IEEE T. Geosci. Remote, 38, 1260-1276, 2000.

Hewison, T. J., Cimini, D., Matrin, L., Gaffard, C., and Nash, J.: Validating clear air ansorption models using ground-based microwave radiometers and vice-versa, Meteorol. Z., 15, 27-36, 2006.

Huang, D., Liu, Y., and Wiscombe, W.: Determination of cloud liquid water distribution using 3D cloud tomography, J. Geophys. Res.-Atmos., 113, D13201, doi:10.1029/2007JD009133, 2008.

Kipp and Zonen: MTP5: air temperature profiles by microwave technologies, available at: http://www.kippzonen.com/ ?downloadcategory/65162/Discontinued+MTP+5.aspx, last access: 16 January, 2012.

Liebe, H. J.: MPM- An atmospheric millimeter-wave propagation model, Int. J. Infrared Milli., 10, 631-649, 1989.

Liljegren, J. C.: Microwave radiometer profiler handbook: evaluation of a new multi-frequency microwave radiometer for measuring the vertical distribution of temperature, water vapour, and cloud liquid water, DOE Atmospheric Radiation Measurement (ARM) Program, Argonne National Lab., Argonne, IL, USA, 2002.

Löhnert, U. and Crewell, S.: Accuracy of cloud liquid water path from ground-based microwave radiometry 1 . Dependency on cloud model statistics, Radio Sci., 38, 8041, doi:10.1029/2002RS002654, 2003.

Löhnert, U., Crewell, S., Krasnov, O., O'Connor, E., and Russchenberg, H.: Advances in Continuously Profiling the Thermodynamic State of the Boundary Layer: Integration of Measurements and Methods, J. Atmos. Ocean. Tech., 25, 1251-1266, 2008. 
Martin, L., Schneebeli, M., and Mätzler, C.: Tropospheric water and temperature retrieval for ASMUWARA, Meteorol. Z., 15, 37-44, 2006 .

Martin, L., Schneebeli, M., and Mätzler, C.: ASMUWARA, a ground-based radiometer system for tropospheric monitoring, Meteorol. Z., 15, 11-17, 2006b.

McClatchey, R. A., Fenn, R. W., Selby, J. E. A., Volz, F. E., and Garing, J. S.: Optical properties of the atmosphere, Tech. Rep. AFCRL-72-0497, Air Force Cambridge Research Laboratory, Hanscom Air Force Base, Bedford, MA, USA, 1972.

OFCM: Federal Meteorological Handbook No. 11: Doppler Radar Meteorological Observations, Part C: WSR-88D Products and Algorithms, Report FCM-H11C-2006, Department of Commerce, NOAA, Washington, D.C., 2006.

Padmanabhan, S., Reising, S. C., Vivekanandan, J., and IturbideSanchez, F.: Retrieval of atmospheric water vapour density with fine spatial resolution using three-dimensional tomographic inversion of microwave brightness temperatures measured by a network of scanning compact radiometers, IEEE T. Geosci. Remote, 47, 3708-3721, 2009.

Petty, G. W.: A First Course in Atmospheric Radiation 2nd Edn., Sundog Publishing, Madison, WI, USA, 2006.

Radiometer Physics GmbH: Profiling Radiometers: HATPRO/HUMPRO/TEMPRO series, available at: http://www. radiometer-physics.de/rpg/html/docs/RPG_MWR_PRO_TN.pdf, last access: 19 August, 2010.

Rose, T., Crewell, S., Löhnert, U., and Simmer, C.: A network suitable microwave radiometer for operational monitoring of the cloudy atmosphere, Atmos. Res., 75, 183-200, 2005.

Rosenkranz, P. W.: Water vapor microwave continuum absorption: A comparison of measurements and models, Radio Sci., 33, 919 928, 1998.

Saavedra, P., Battaglia, A., and Simmer, C.: Partitioning of cloud water and rainwater content by ground-based observation with the Advanced Microwave Radiometer for Rain Identification (ADMIRARI), J. Geophys. Res.-Atmos., 117, D05203, doi:10.1029/2011JD016579, 2012.
Schween, J. H., Crewell, S., and Löhnert, U.: Horizontal-humidity gradient from one single-scanning microwave radiometer, IEEE Geosci. Remote Sens., 8, 336-340, 2011.

Shupe, M. D., Daniels, J. S., de Boer, G., Eloranta, E. W., Kollias, P., Long, C. N., Luke, E. P., Turner, D. D., and Verlinde, J.: A focus on mixed-phase clouds: the status of ground-based observational methods, B. Am. Meteorol. Soc., 89, 1549-1562, 2008.

Staelin, D. H.: Measurements and interpretation of the microwave spectrum of the terrestrial atmosphere near 1-centimeter wavelength, J. Geophys. Res., 71, 2875-2881, 1966.

Stogryn, A. P., Bull, H. T, Rubayi, K., and Iravanchy, S.: The microwave permittivity of sea and fresh water, GenCorp Aerojet, Azusa, CA, USA, 1995.

Turner, D. D., Cadeddu, M. P., Löhnert, U., Crewell, S., and Vogelmann, A. M.: Modifications to the water continuum in the microwave suggested by ground-based $150-\mathrm{GHz}$ observations, IEEE T. Geosci. Remote, 47, 3326-3109, 2009.

Ulaby, F. T., Moore, R. K., and Fung, A. K.: Microwave Remote Sensing: Active and Passive, Vol. I - Microwave Remote Sensing Fundamentals and Radiometry, Arctech house, Norwood, MA, USA, 1981.

Ware, R., Carpenter, R., Güldner, J., Liljegren, J. C., Nehrkom, T., Solheim, F., and Vandenberghe, F.: A multichannel radiometric profiler of temperature, humidity, and cloud liquid, Radio Sci., 38, 8079, doi:10.1029/2002RS002856, 2003.

Westwater, E. R., Decker, M. T., Zachs, A., and Gage, K. S.: Ground-based remote sensing of temperature profiles by a combination of microwave radiometry and radar, J. Clim. Appl. Meteorol., 22, 126-133, 1983. 